\title{
DÖRT AYAKLI ROBOTLARIN MODELLENMESİ, KONTROLÜ VE ENGEBELİ YÜZEYLERDE YÜRÜYÜŞÜ ÜZERINNE BİR LİTERATÜR ARAŞTIRMASI
}

\author{
${ }^{1}$ Muhammed Arif ŞEN (D) , ${ }^{2}$ Mete KALYONCU \\ 1,2 Konya Teknik Üniversitesi, Mühendislik ve Doğa Bilimleri Fakültesi, Makina Mühendisliği Bölümü, \\ Konya, TÜRKIYYE \\ ${ }^{1}$ masen@ktun.edu.tr, ${ }^{2}$ mkalyoncu@ktun.edu.tr
}

(Geliş/Received: 01.10.2020; Kabul/Accepted in Revised Form: 20.11.2020)

ÖZ: Robotik alanındaki gelişmelerin günümüzdeki en belirgin örneklerinden birisi olan dört ayaklı robotlar; doğadaki hayvanlardan esinlenerek geliştirilen ve üstün hareket kabiliyetleri sayesinde tekerlekli sistemlerin sınırlı kaldığı dinamik hareketleri ustalıkla gerçekleştirebilen, eklemli bacak yapısına sahip, yürüyen mobil sistemlerdir. Bu çalışmada, literatürde öne çıkan mevcut dört ayaklı robotlar ve bu robotların modellemesi, eyleyici türleri, düz ve engebeli zeminlerde yürüyüşü ve kontrolü üzerine yapılan araştırmalar sunulmuştur. Karmaşık bir sistem olması nedeniyle belirli konuların incelendiği sınırlı derlemelerin aksine, bu çalışmada geniş bir literatür derlenmiştir. Girişte, dört ayaklı robotların üstün özelliklerine ve bu alandaki araştırmaların temel motivasyon kaynaklarına değinilmiştir. Öncelikle, son yılarda geliştirilen dört ayaklı robotlar ve teknik özellikleri kronolojik sırayla belirtilmiştir. Devamında, bacaklı sistemler için önerilen modelleme ve kontrol yöntemlerine ve yaygın kullanılan eyleyicilere ait örnekler sunulmuştur. Sonrasında, dört ayaklı robotların diğer mobil robotlara kıyasla önemli bir avantajı olan, engebeli yüzeylerde yürüyüş ve denge-hareket kontrolü ile ilgili temel yaklaşımların yanı sıra güncel teorik ve uygulamalı çalışmalar sunulmuştur. Sonuç kısmında ise, dört ayaklı robotik alanında devam eden çalışmalara ve yakın gelecekte gerçekleşmesi muhtemel gelişmelere değinilmiştir.

Anahtar Kelimeler: Bacaklı robotik, Dört ayaklı robotlar, Yürüyüş kontrolü, Engebeli yüzey

\section{A Literature Review on Modeling, Control and Walking on Rough Surfaces of Quadruped Robots}

\begin{abstract}
Quadruped robots, one of the most considerable samples of the developments in robotics nowadays; are mobile systems that are inspired by animals in nature and can perform dynamic movements in which wheeled systems are limited thanks to their superior abilities, and have a jointed leg structure. In this study, the existing prominent quadruped robots in the literature and the modeling of these robots, types of actuators, gait, and control on flat and rough surfaces are presented. Due to its complex structure, a wide literature is reviewed in this study, unlike the limited reviews in which investigate specific subjects. In the introduction, the advantage of quadruped robots and the main motivation sources of researches in this field are mentioned. First of all, quadruped robots developed in recent years, and their technical features are specified in chronological order. Next, proposed modeling and control methods for legged systems and examples of commonly used actuators are presented. Afterward, as well as basic approaches, theoretical and experimentally studies are presented, to walking on rough surfaces and balance-motion control, which is an important advantage compared to other mobile robots. In the conclusion section, the continuing studies and probable forthcoming improvements in the field of quadruped robotics are mentioned.
\end{abstract}

Key Words: Legged robotics, Quadruped robots, Gait control, Rough/Uneven surface 


\section{GİRİŞ (INTRODUCTION)}

İnsanoğlu varoluşundan itibaren doğadaki canlıları incelemeye, onların etkileyici yeteneklerinden ve sezgisel davranışlarından ilham alarak, yaşadığı çağın yenilikçi fikirlerini üretmeye ve hayatını kolaylaştıracak yeni teknolojiler geliştirmeye gayret etmiştir. Bu çabanın son yıllardaki en belirgin örneklerinden birisi; üstün kabiliyetleri sayesinde mükemmel yürüyüşler sergileyen, dinamik hareketleri ustalıkla gerçekleştirebilen, hayvanlardan esinlenerek geliştirilmiş dört ayaklı robotlardır.

Geleneksel tekerlekli/paletli mobil robotlara kıyasla, belirli bir yol veya ray üzerinde ilerlemek zorunda olmadan, zorlu arazi şartlarında dahi yüksek hareket kabiliyeti sayesinde önemli görevleri yerine getiren bacaklı robotlar; biyolojik canlılara benzerliği sebebiyle insanların dikkatini çekmekte, geliştirilmeye müsait yönlerinin çeşitliliği sayesinde robotik alanındaki yerini giderek artırmaktadır.

Tekerlekli bir sistemin hareketi zemin koşulları ile sınırlı kalmak zorunda iken, tasarlanabilir bir bacak yapısı ve kontrol edilebilir bir yürüyüş ile bulunduğu zeminle etkileşimli ancak engeller ile kısıtlı olmadan hareket edebilen bacaklı robotlar, araştırmacıları heyecanlandırmakta ve motive etmektedir. Ancak, insanlara ve kendilerine zarar vermeyecek güvenli bir bacaklı robot geliştirmek, teknolojik açıdan önemli ancak uzun bir çaba gerektiren karmaşık bir görevdir.

Bacaklı bir robotun en az sayıda bacağa sahip olması, toplam gövde kütlesinin azalması ve bacaklar arası koordinasyonun kolaylaşması açısından avantajlıdır. Ayrıca, bacak sayısı azaldıkça zemin ile temas da azaldığ i ç̧in robotun zorlu arazilerde hareketi daha uygun hale gelir. Ancak, bacaklı robotların en temel problemi olan denge problemi bacak sayısının azalmasıyla dramatik bir şekilde artmaktadır. Robotun dinamik olarak kararlı olabilmesi için ağırlık merkezinin yerini değiştirebilecek veya düzenleyici kuvvetler uygulayarak kendisi aktif dengeleyebilecek minimum bacak sayısına sahip olması gerekir. Bu sebeple bacaklı bir robotun inşa sürecinde tanımlanacak ilk özellik bacak sayısıdır. Bu sayı, stabilite ve güvenilirlik gibi robotun sahip olması gerekli temel özellikler ile; hız, en az ağırlık ve maliyet gibi özel uygulama gereksinimleri arasındaki bir dengenin kurulması sonucu belirlenir.

Tek ayaklı robotlar (Şekil 1a), zemine tek bir noktadan temas halinde ve ziplayarak hareket ederler. Hareketsiz halde dahi dengelenmeye muhtaç, oldukça kararsız bir yapılardır. Asimo gibi iki ayaklı insansı robotlar (Şekil 1b), zemine ayak tabanları ile yüzeysel temas ettikleri için statik halde dengededirler. Ancak, yürüyüş sırasında bir bacak adım atarken, diğer bacağın tüm gövde ağırlı̆̆ını destekleyecek ve dengeleyecek bir yapıya sahip olması gerekir. Altı ayaklı robotlar (Şekil 1c) (Genghis-MIT) ise, stabil bir yürüyüş ve kontrol edilebilirlik açısından en avantajlı robotlar olsa da bacak sayısının artması farklı problemleri beraberinde getirmektedir. Gövde dengesini garanti edecek sayıdan fazla bacak kullanmak; toplam kütlenin artmasına, bacaklar arası koordinasyonun karmaşıklaşmasına ve maliyetin yükselmesine sebep olmaktadır. Optimum bacak sayısı kararlılık, karmaşıklık, toplam kütle ve maliyet açısından değerlendirildiğinde, dört ayaklı robotların (Şekil 1d) (Spot) daha optimum çözümler sunabileceği görülmektedir. Serbest hareketli bir kütleyi dengede tutmak için en az üç noktadan kuvvet uygulamak gerekir. Benzer şekilde, statik kararlı bir yürüyüş için de en az üç noktadan zemin ile temas gerekmektedir. Dört ayaklı robotlarda bir bacak adım atarken diğer üç bacak zeminle temas ederek gövdeyi taşır ve hareket ettirir. Böylece, zemindeki ayaklar gövde dengesini garanti eden bir destek üçgeni oluşturarak, robotun kararlı bir şekilde yürümesini sağlarlar.

Genel olarak dört ayaklı robotlar, tek ve iki ayaklı robotlara kıyasla daha kararlı ve güvenilir, altı ve daha fazla ayaklı robotlara kıyasla daha az karmaşık, hafif ve ucuz olabilmektedir. Diğer bir ifadeyle; dört ayaklı robotların, güvenli ve kararlı bir yürüyüş ile kolay kontrol edilebilirlik ve toplam kütle arasında bir dengenin kurulabilmesi için gerekli en ideal bacak sayısına sahip olduğu söylenebilir.

Dört ayaklı robotların, tekerlekli sistemlere kıyasla en belirgin avantajı ve zorlu görevler için tercih edilmesini sağlayan özelliği, düzensiz arazide hareket edebilme kabiliyetidir. Düzensiz arazilerde hareketin ve denge kontrolünün karmaşık olması nedeniyle, çalışmalar çoğunlukla robotun düz yüzeylerde ki hareketlerine odaklanmamıştır. Ancak, engebesiz bir yüzeyde robottan istenen hareketi elde edebilmek için bacak koordinasyonları ve adımlar daha esnek seçilebilmesine karşın, engebeli bir arazide yürüyüş planlamasının ve kararlı bir gövde hareketinin sağlanabilmesi önem arz etmektedir. Yani, engebeli arazide robotun hareketliliğini belirleyen ve sınırlayan zemindeki düzensizliklerdir. 
a)

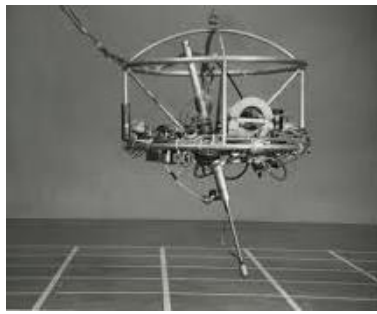

b)

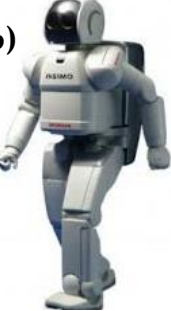

c)

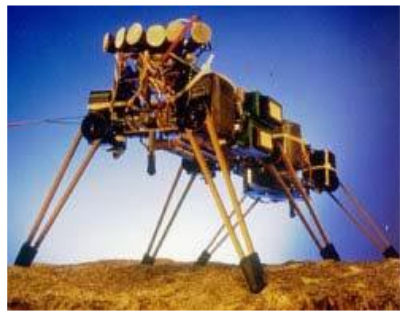

d)

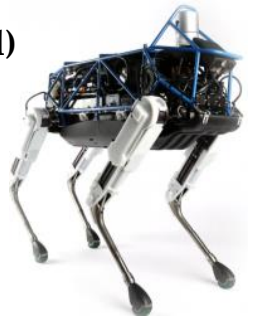

Şekil 1. a) Tek, b) İki, c) Altı ve d) Dört ayaklı robotlar Figure 1. a) One leg, b) Biped, c) Six legs and d) Quadruped legged robots

Bacaklı mobil robotlar, literatürde yeni olmamasına rağmen, gelişen teknoloji ile çeşitlenmekte ve halen araştırmacıların dikkatini çekmektedir. Dış çevreye ve yol şartlarına bağlı olmadan neredeyse her yerde hareket edebilen ayaklı yürüyen sistemler kurma fikri, araştırmacıları etkilemektedir. Bacaklı yürüyüşün (legged locomotion) sahip olduğu yüksek hareket kabiliyeti; engebeli arazi şartlarında arama-kurtarma, yük ve canlı taşıma vb. gibi önemli görevlerde, geleneksel yöntemlere kıyasla büyük avantaj sağlamakta ve bu alandaki çalışmaları motive etmektedir. Dört ayaklı robotlar ile ilgili yapılan çalışmaların sayısı artış eğilimde ancak, sistemin karmaşık dinamik yapısı nedeniyle bacaklı robotik alanında ki araştırmalar halen ileri düzey teorik hesaplamalar gerektirmektedir. Bu nedenle, dünya genelinde birkaç kurum hariç, kayda değer deneysel çalışmalar yapılamamakta ve bacaklı robot teknolojisinin laboratuvar ortamından çıkıp ticarileşmesi uzun sürmektedir.

\section{DÖRT AYAKLI ROBOTLARA GENEL BAKIŞ (OVERVIEW OF QUADRUPED ROBOTS)}

Son on yıldaki bacaklı robotlar üzerine yapılan araştırmalar ve eyleyici, sensör, yazılım, donanım vb. gibi alanlardaki teknolojik gelişmeler; biyolojik canlılara benzer, çok yönlü ve çevik hareket etme potansiyeline sahip bacaklı yürüyebilen mobil robotların geliştirmesinin önünü açmıştır. Özellikle, dinamik hareketler için yeterli beceriye sahip dört ayaklı robotlar geliştirilmeye başlanmıştır. Tekerlekli sistemlere göre üstün olmalarına rağmen, bacaklı robotların performansı, esinlenerek geliştirildikleri canlılara kıyasla halen yetersiz kalmaktadır. Çünkü dinamiklerini ve çevreleriyle etkileşimlerini kontrol etmek için yeni yöntemler, algoritmalar tasarlamak veya mevcut olanları geliştirebilmek halen büyük bir zorluk teşkil etmektedir. Bacaklı yürüyüş kontrolü için, farklı yöntemlere ve arazinin türüne bağlı olarak değişkenlik (adaptasyon) göstermesi gereken yeni yaklaşımlara ihtiyaç duyulabilmektedir. Bu nedenle, özellikle yüksek hız ve ivmelerde, robot dinamiklerinin ve gövde dengesinin kontrolüne yönelik çalışmalar önem arz etmektedir (Michele, 2013).

Geçmişteki otonom yürüyüş makinelerinin ilk başarılı örneklerinden birisi, Liston ve Mosher (1968) tarafından, General Electric firması adına geliştirilen hidrolik tahrikli 'Walking Truck' isimli dört ayaklı makinedir. Şekil 2' den anlaşılacağ üzere, bu makine $1400 \mathrm{~kg}$ ağırlığında ve oldukça büyük boyutlarda (3530 x 1066 x $4572 \mathrm{~mm}$ ) olmasına rağmen, bacakların hareketi için yüksek kazançlı pozisyon kontrolü kullanılmasından dolayı, 8 km/s yürüyüş hızına kadar çıkabilmekteydi.

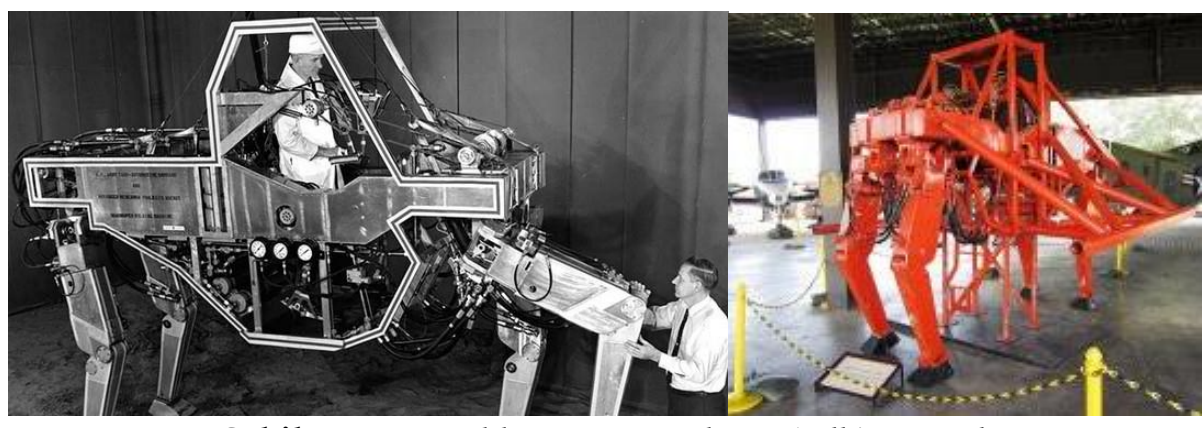

Şekil 2. Dört ayaklı otonom makine Walking Truck

Figure 2. Quadruped autonomous machine Walking Truck 
Marc Raibert, Carnegie Mellon Ünv. ve sonrasında Massachusetts Teknoloji Enstitüsünde yaptı̆̆1 çalışmalar sonrasında, Boston Dynamics firmasının (Boston Dynamics, 2020) kurucusu ve yöneticisi olarak bu alanda önemli bir otorite olmuştur. İlk çalışmalarına, 1979 yılında tek bacaklı zıplayan robotlar ile başlayan Raibert, bacaklı robotlar alanında yaptığı önemli ve yol gösterici çalışmalar ile araştırmacılara ilham kaynağı olmuştur. Raibert'ın, tek (Monoped), iki (Biped) ve dört ayaklı (Quadruped) robotları Şekil 3'te gösterilmiştir (Raibert, 1986). Tek bacaklı zıplama hareketinde; zıplama yüksekliğini, gövde duruşunu ve ilerleme hızını birbirinden bağımsız olarak kontrol etmiştir (Silva ve Tenreiro Machado, 2007). Daha sonra önerdiği bu kontrol algoritmasını iki ve dört ayaklı sistemler için de uygulamıştır.
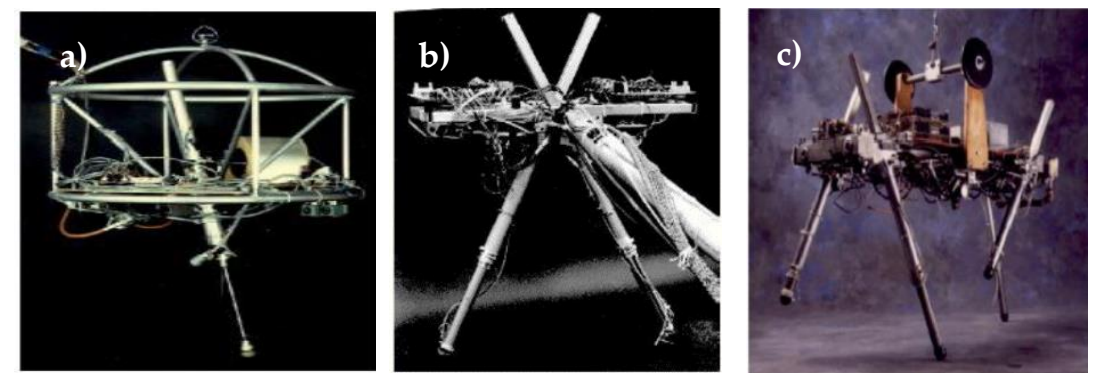

Şekil 3. Raibert tarafından geliştirilen a) Tek, b) İki ve c) Dört ayaklı robotlar Figure 3. $\boldsymbol{a}$ ) Single, $\boldsymbol{b}$ ) Two and c) Four legged robots developed by Raibert

Bacaklı robotlar pnömatik, hidrolik ve elektrikli eyleyiciler ile tahrik edilmektedir. Elektrikli eyleyiciler kolay kontrol edilebilirliği, boyut ve maliyet avantajları nedeniyle, öncelikli olarak tercih edilmektedir. Ancak, güç yoğunluklarının yetersiz olması nedeniyle yüksek dinamik hareketler için mekanik enerji depolayan yayların kullanılmasını gerektirmektedir. Yaylar, robotun doğal dinamiklerini kullanabilme kapasitesini artırmakla birlikte, iş yükünü azaltarak enerji tasarrufu sağlamakta ve pasif dinamik yürüyüş konusunda geniş bir araştırma alanı oluşturmaktadır (McGeer, 1990). Bu sebeple, çıkışlarında elastik bileşenlerin bulunduğu, yüksek çevrim oranına sahip Seri Elastik Eyleyiciler yaygın olarak kullanılmaktadır (Pratt, 2002). 1990'lı yıllarda geliştirilmeye başlanan Scout I isimli robot, elektrikli eyleyici kullanılarak geliştirilen ilk robotlardandır (Yamazaki, 1999). Raibert'ın robotlarından sonra, Sang-Ho Hyon ve ark. tarafından 1998 yılında geliştirilmeye başlanan KenKen I isimli robot, hidrolik tahrikli robotların belirgin bir örneğidir (Hyon ve ark., 2003b). Krupp ve Pratt tarafından geliştirilen tek bacaklı bir robotta, ilk defa hidro-elastik eyleyiciler kullanılmıştır. (Krupp ve Pratt, 2006). 2008 yılında geliştirilen Airhopper isimli robotta ise pnömatik eyleyiciler kullanılmıştır. Semini (2010), bacaklı robotların eyleyicileri üzerine kapsamlı bir çalışma sunmuştur.

Poulakakis ve ark. (2005), Mcgill Üniversitesi'nde 1990 yılında geliştirmeye başladıkları prizmatik bacak yapısına sahip Scout I isimli robotun (Şekil 4a) devamı olarak, 1999 yılında dörtnala koşabilen Scout II isimli robotu (Şekil 4b) geliştirmişlerdir. Robotun iki uzuvlu bacak yapısı, sadece düzlemsel dairesel hareketli tek bir eyleyici ile gövdeye bağlıdır. Basit bir mekanizmaya sahip olmasına rağmen dinamik olarak kararlı bir şekilde koşabilme kabiliyetine sahiptir.
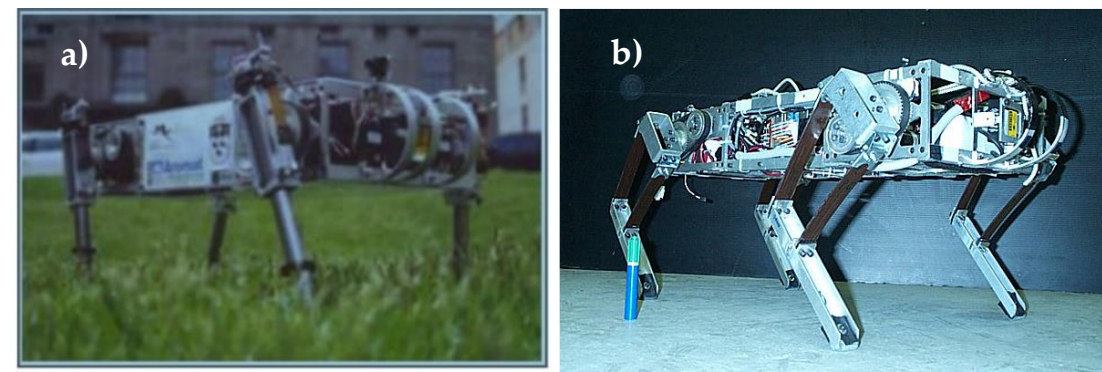

Şekil 4. Elektrik tahrikli dört ayaklı robotlar, a) Scout I ve b) Scout II Figure 4. Electric driven quadruped robots, a) Scout I and b) Scout II 
Hyon ve ark. (2003a), geliştirdikleri tek bacaklı KenKen I isimli robotun (Şekil 5a) ardından, iki bacaklı KenKen II isimli robotu (Şekil 5b) geliştirmişlerdir. Dört bacaklı versiyonunu ise hayata geçirememişler, ancak bu konuda önemli sonuçlar sunmuşlardır. Bacak yapısı, hidrolik tahrikli kalça (hip) ve baldır (knee) eklemlerinin yanı sıra yay ile pasif hareketli ve zemin ile temas sensörü içeren bir ayak bileğiden (ankle) oluşur. Güç ünitesi hariç, valfler ve kontrol bileşenleri robotun bünyesindedir. KenKen robotunun bacak yapısı, sonrasında geliştirilen hidrolik bacaklı robotlara ilham kaynağı olmuştur.
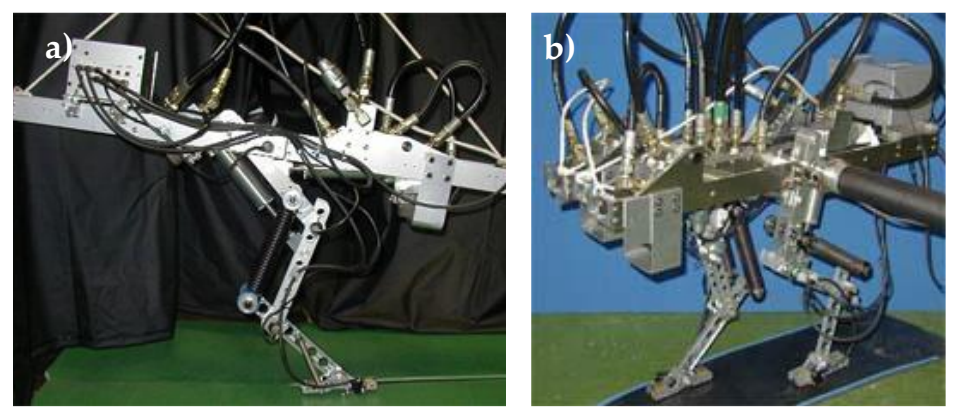

Şekil 5. Hidrolik tahrikli dört ayaklı robotlar, a) KenKen I ve b) KenKen II

Figure 5. Hydraulically driven quadruped robots, a) KenKen I and $\boldsymbol{b}$ ) KenKen II

Dört ayaklı robotlar; çalışma konularına, kullanım amaçlarına ve esinlenildiği biyolojik canlıların fiziksel özelliklerine göre farklı boyutlarda tasarlanmıştır. Hiroshi Kimura tarafından geliştirilen, elektrik tahrikli Tekken II isimli robot (Şekil 6a), ağırlığı $4.3 \mathrm{~kg}$ ve uzunluğu $0.3 \mathrm{~m}$ olan küçük boyutlu bir robottur. Ayrıca Kimura, mekanik sistemin doğal dinamiklerini kullanarak, dört ayaklı sıçrama (bounding) hareketi üzerine çalışmalar yapmıştır (Kimura ve ark., 1999; Zhang ve ark., 2006). Stanford Üniversitesinde Kenneth Waldron tarafından elektrik tahrikli olarak geliştirilen, $80 \mathrm{~kg}$ ağırlı̆̆ında ve $1.75 \mathrm{~m} \times 0.6 \mathrm{~m} \times 0.8 \mathrm{~m}$ boyutlarında KOLT isimli robot (Şekil 6b), büyük boyutlu dört ayaklı robotların belirgin bir örneğidir (Estremera ve Waldron, 2008).
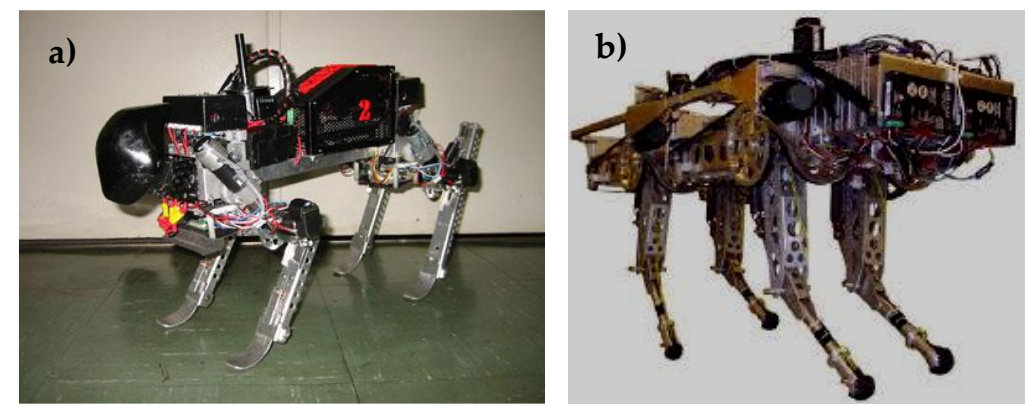

Şekil 6. Küçük ve büyük boyutlu dört ayaklı robotlar, a) Tekken II ve b) KOLT

Figure 6. Small and large quadruped robots, a) Tekken II and b) KOLT

Marc Raibert ve arkadaşları, 1922 yılında kurdukları Boston Dynamics firmasında; otonom 50 kg yük taşıma kapasitesi olan, engebeli alanlarda ve yüksek hızlarda dinamik yürüyebilen dört bacaklı robotlar geliştirmek üzerine çalışmalara başlamışlardır. 2005 yılında, Amerikan ordusunun Savunma Gelişmiş Araştırma Projeleri Ajansı (DARPA) tarafından finanse edilen, BigDog isimli dört ayaklı robotun ilk versiyonunu sunmuşlardır (Şekil 7a). Her bir bacağı dört uzuvlu olan hidrolik tahrikli BigDog-2005 versiyonu, $1 \mathrm{~m} \times 0.3 \mathrm{~m} \times 1 \mathrm{~m}$ boyutlarında ve $90 \mathrm{~kg}$ ağırlı̆̆ındadır (Buehler ve ark., 2005). Boston Dynamics firması, 2006 yılında yayınladığı çalışmalarında (Buehler ve ark., 2006; Playter ve ark., 2006), eğimli yüzeylerde yürüyebilen, çapraz ( $X$ şeklinde) bacak düzenine sahip BigDog-2006 versiyonunu etkileyici bir video ile sunmuştur (Şekil $7 \mathrm{~b}$ ). Ancak, bacak yapısının neden değiştirildiği hakkında bilgi verilmemiştir. 2008 yılında, karlı ve ormanlık bir arazide yürüyebildiği görülen, dış bozucu girişlere karşın dengesini koruyabilen, daha fazla yük taşıma kapasitesine sahip BigDog-2008 isimli yeni bir versiyonu daha yayınlanmıştır (Şekil 7c). 
Raibert ve ark. (2008), BigDog-2008 versiyonunun tasarımını kısa bir bildiri ve video kaydı ile tanıtmışlar, diğer versiyonlara göre en belirgin farkının; ek bir aktif dönme eklemi içeren, yeni bir kinematik yapıya sahip olduğunu belirtmişlerdir. Bu alanda en popüler yayınlardan biri olan bu bildiride, ne yazık ki çok az ayrıntı yer almaktadır ve ilave dönme ekleminin nedenlerinden söz edilmemektedir. Sonraki yıllarda, Boston Dynamics firması BigDog'un gelişimini ve hareket kabiliyetini sergileyen birkaç video daha yayınlanmıştır. Ancak, Amerikan ordusu destekli geliştirilmesi ve gizlilik gibi nedenlerden dolayı, bacaklı robotik alanda büyük ilham kaynağı olan BigDog robotunun tasarımı, kontrolü, bileşenleri ve teknik özellikleri hakkında çok az bilgi ve bilimsel yayın mevcuttur.
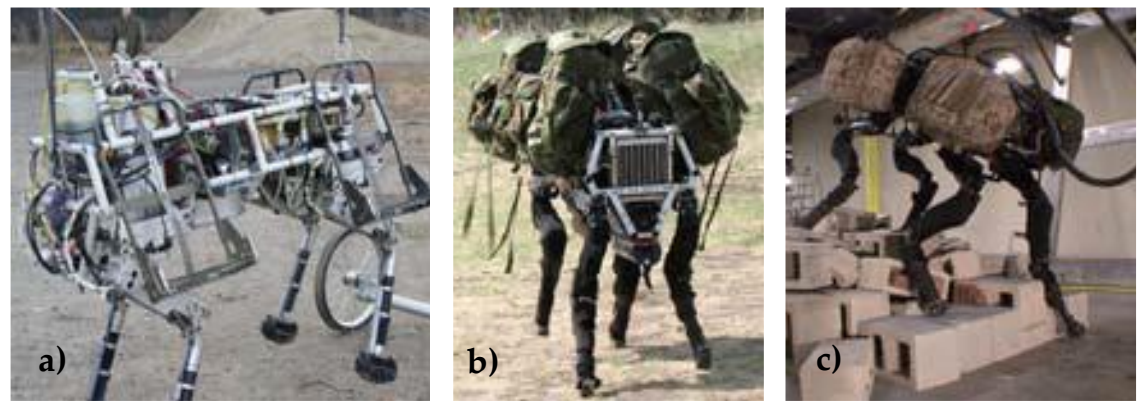

Şekil 7. Boston Dynamics firmasının ilk robotu, a) BigDog-2005, b) BigDog-2006 ve c) BigDog-2008 Figure 7. Boston Dynamics company's first robot, a) BigDog-2005, b) BigDog-2006 and c) BigDog-2008

Son yılarda geliştirilen dört ayaklı robotların görselleri, fiziksel özellikleri ve maksimum yürüyüş kapasiteleri gibi genel teknik detayları aşağıda tarihsel sıraya göre sunulmuştur. Bakırcıŏ̆lu ve Kalyoncu (2020) tarafından bacaklı robotların geneli hakkında bir literatür çalışması sunulmuştur.

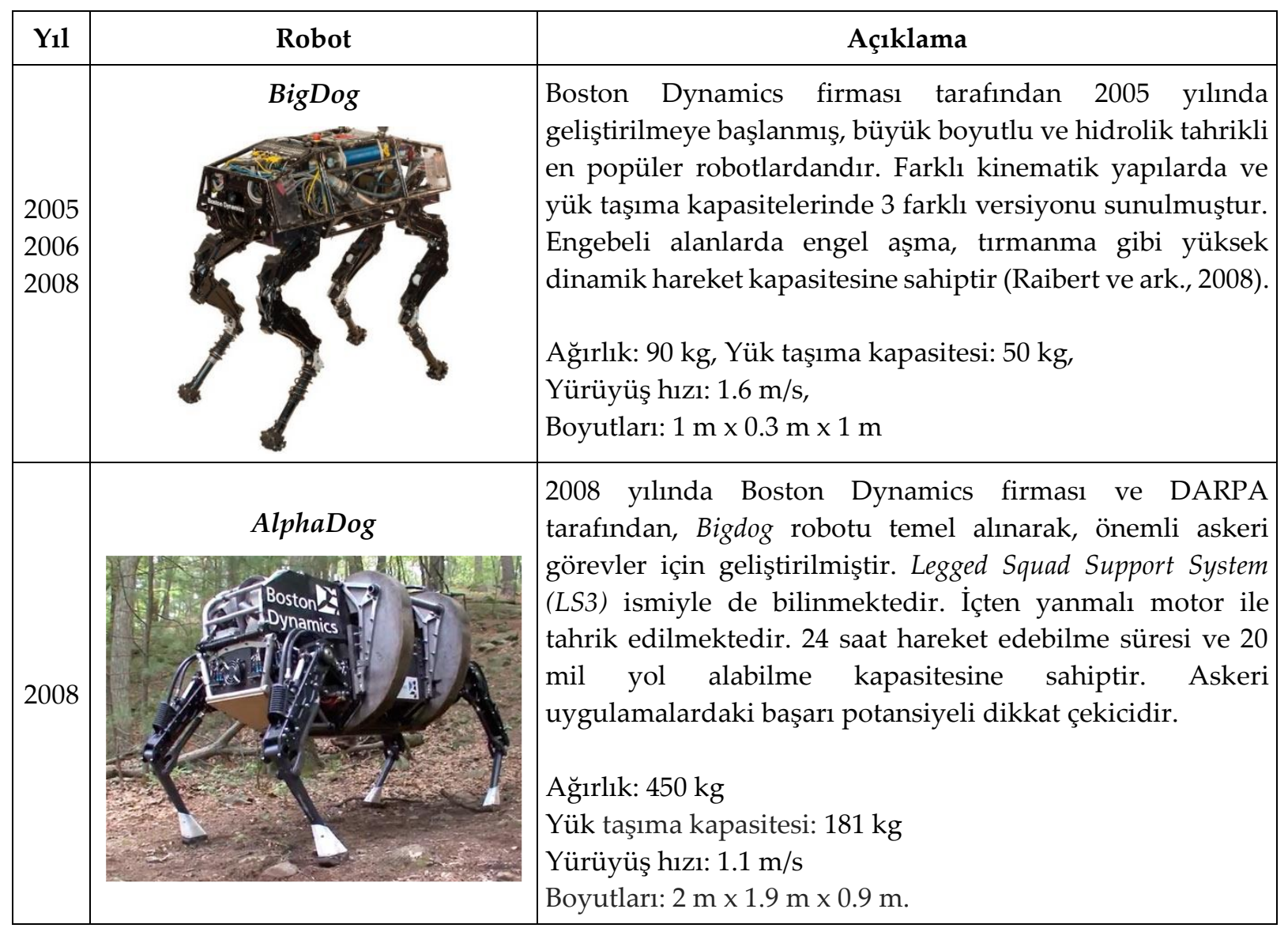




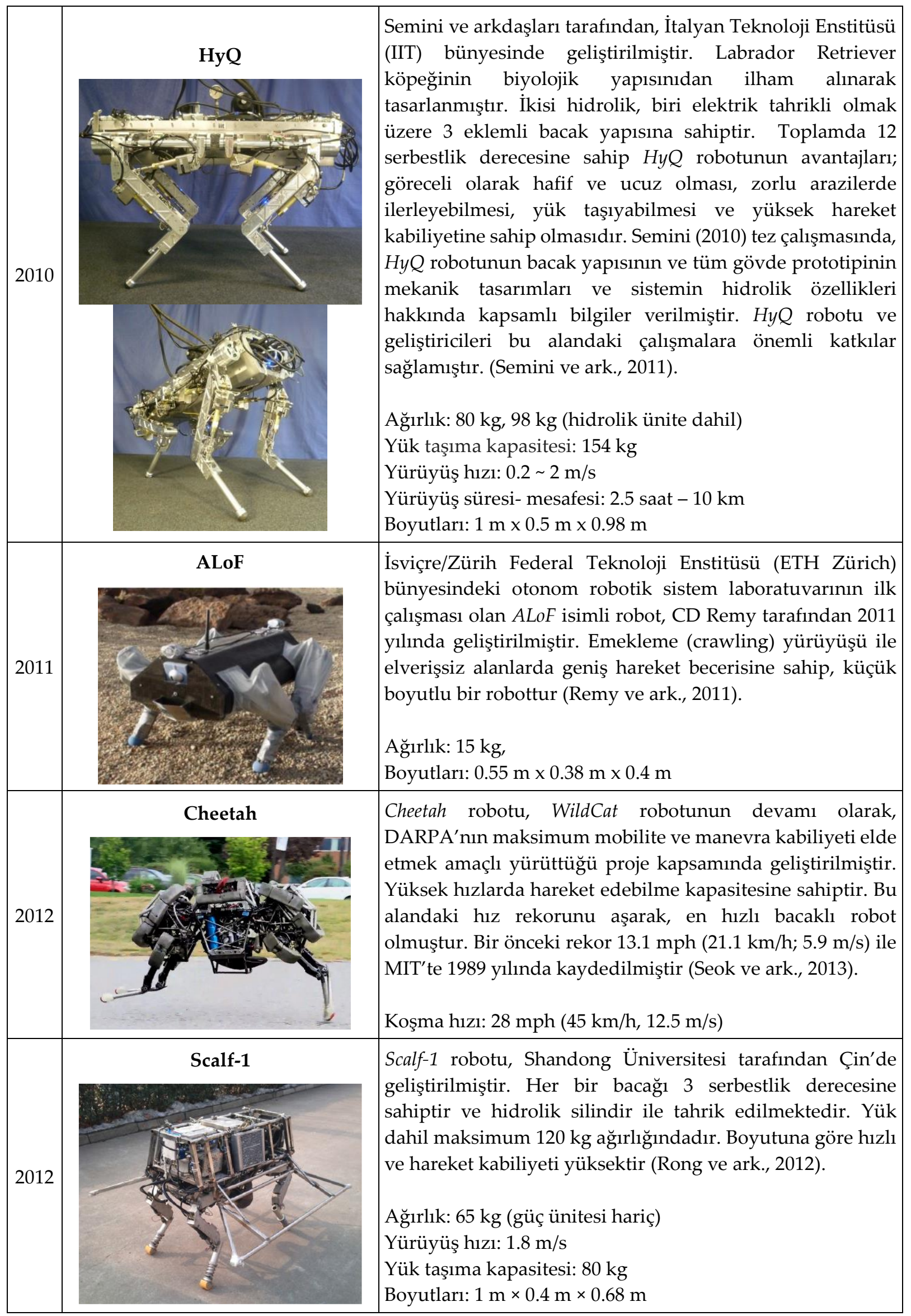




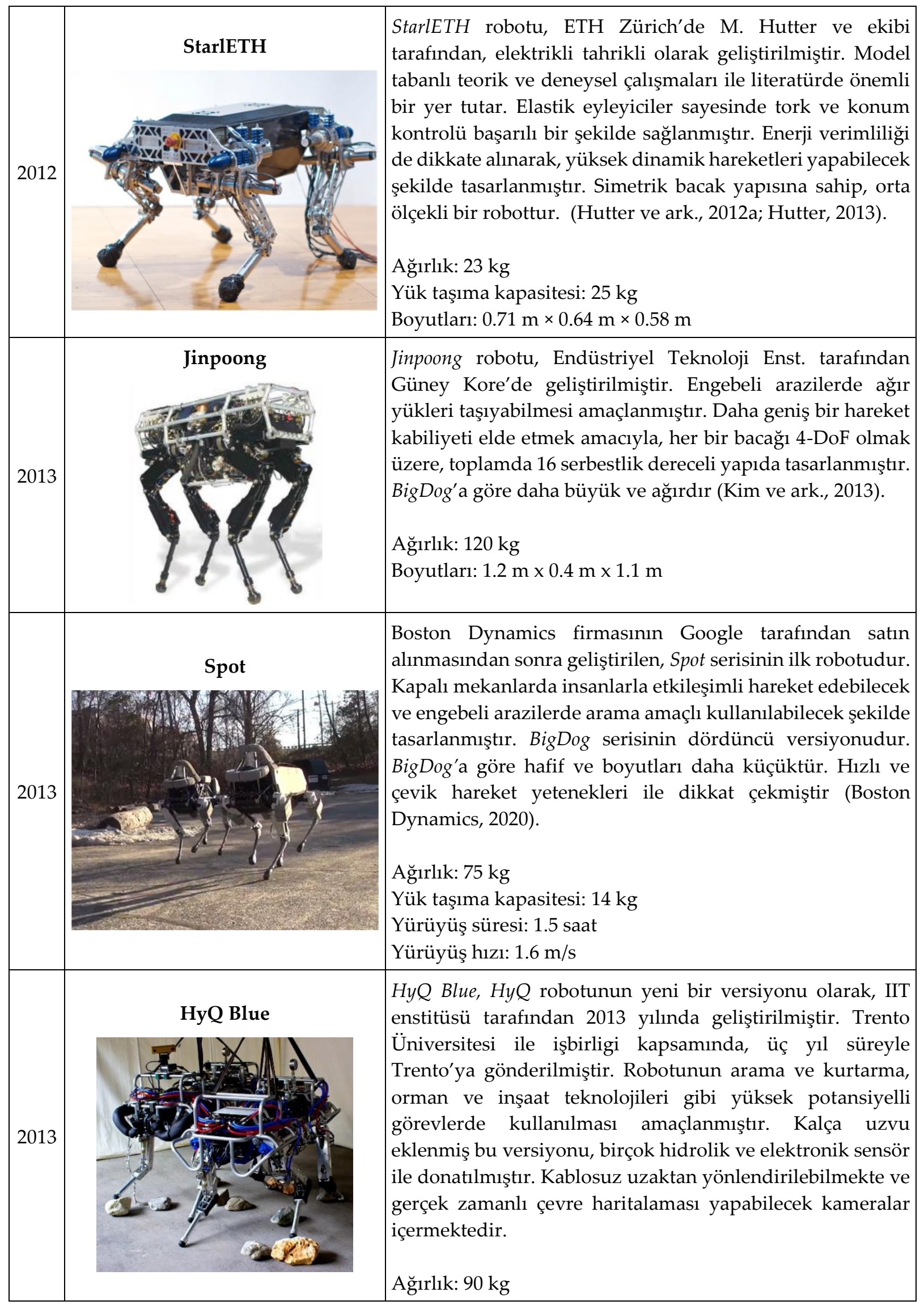




\begin{tabular}{|c|c|c|}
\hline 2014 & lephant & $\begin{array}{l}\text { Baby Elephant, yüksek yük taşıma amacıyla, fil görünümlü } \\
\text { olarak geliştirilmiştir. Seri-paralel hibrit mekanizma } \\
\text { şeklinde tasarlanan bacak yapısı, } 3 \text { serbestlik dereceli ve } \\
\text { hidrolik silindirler ile tahrik edilmektedir. Zemin tepkisini } \\
\text { azaltmak için ayak ucuna yay eklenmiştir. Araştrımacılar bu } \\
\text { robotta kullanmak üzere, "Hy-Mo" isimli bir mikro-motor } \\
\text { kontrolcü, filtre, soğutucu, akümülatör ve tank } \\
\text { gerektirmeyen yeni bir hidrolik eyleyici geliştirmişlerdir } \\
\text { (Gao ve ark., 2014). } \\
\text { Ağırlık: } 130 \mathrm{~kg} \text {, Yürüyüş hızı: } 0.5 \mathrm{~m} / \mathrm{s} \\
\text { Boyutları: } 1.2 \mathrm{~m} \times 0.6 \mathrm{~m} \times 1 \mathrm{~m}\end{array}$ \\
\hline 2015 & MiniHyQ & $\begin{array}{l}\text { HyQ ekibi tarafından tasarlanmış ve şimdiye kadar inşa } \\
\text { edilmiş en hafif ve en küçük hidrolik dört ayaklı robot } \\
\text { ünvanına sahiptir. MiniHyQ tamamen tork kontrollü olup } \\
\text { geniş hareket kabiliyetine sahiptir ve güç ünitesi } \\
\text { üzerindedir. HyQ ile yaklaşık aynı boyutlara sahip olmasına } \\
\text { ragmen } 3 \text { kat daha hafif, \% } 30 \text { daha fazla tork gücüne sahip } \\
\text { ve eklem hareket aralı̆̆ } \% 40 \text { daha fazladır. Bacağın dönme } \\
\text { eksenini değiştirebilmek için alt ve üst eklemlerin boyları } \\
\text { ayarlanabilmektedir. Robot bacaklarına ait uzuvlar tam } \\
\text { kapalı olduğunda \%15 kısalabilmektedir. Ağırlığı, hidrolik } \\
\text { güç ünitesi hariç, sadece } 24 \text { kg'dir. Bir kişi tarafından } \\
\text { kolayca taşınabilir. Robotu hafifletmek için minyatür } \\
\text { hidrolik eyleyiciler kullanılmıştır. Ayrıca, diz eklemlerinde } \\
\text { Isogram mekanizması kullanılmıs, mekanizma ile uyumlu } \\
\text { bir tork sensörünün tasarımı önerilmiştir. (Khan, } 2015 \text {; Khan } \\
\text { ve ark., } 2015 \text { ) } \\
\text { Ağırlık: } 35 \mathrm{~kg} \text {, Boyutları: } 0.85 \mathrm{~m} \times 0.35 \mathrm{~m} \times 0.77 \mathrm{~m} \\
\text { Yürüyüş hızı: } 2.5 \mathrm{~m} / \mathrm{s}\end{array}$ \\
\hline 2015 & & 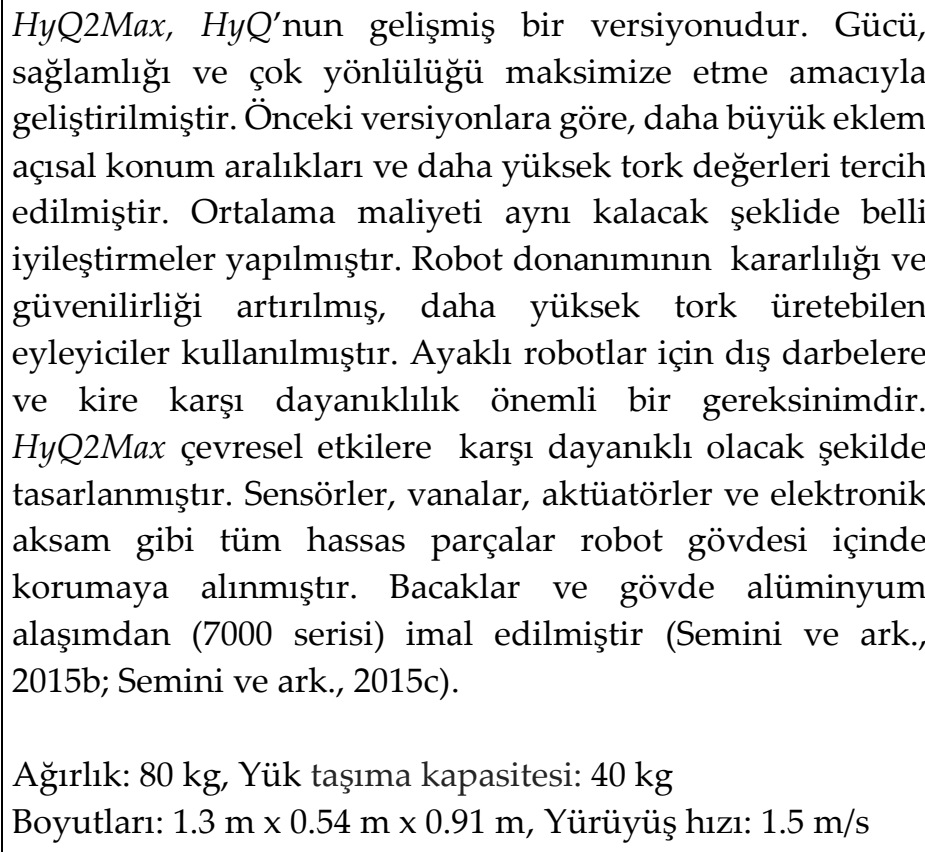 \\
\hline
\end{tabular}




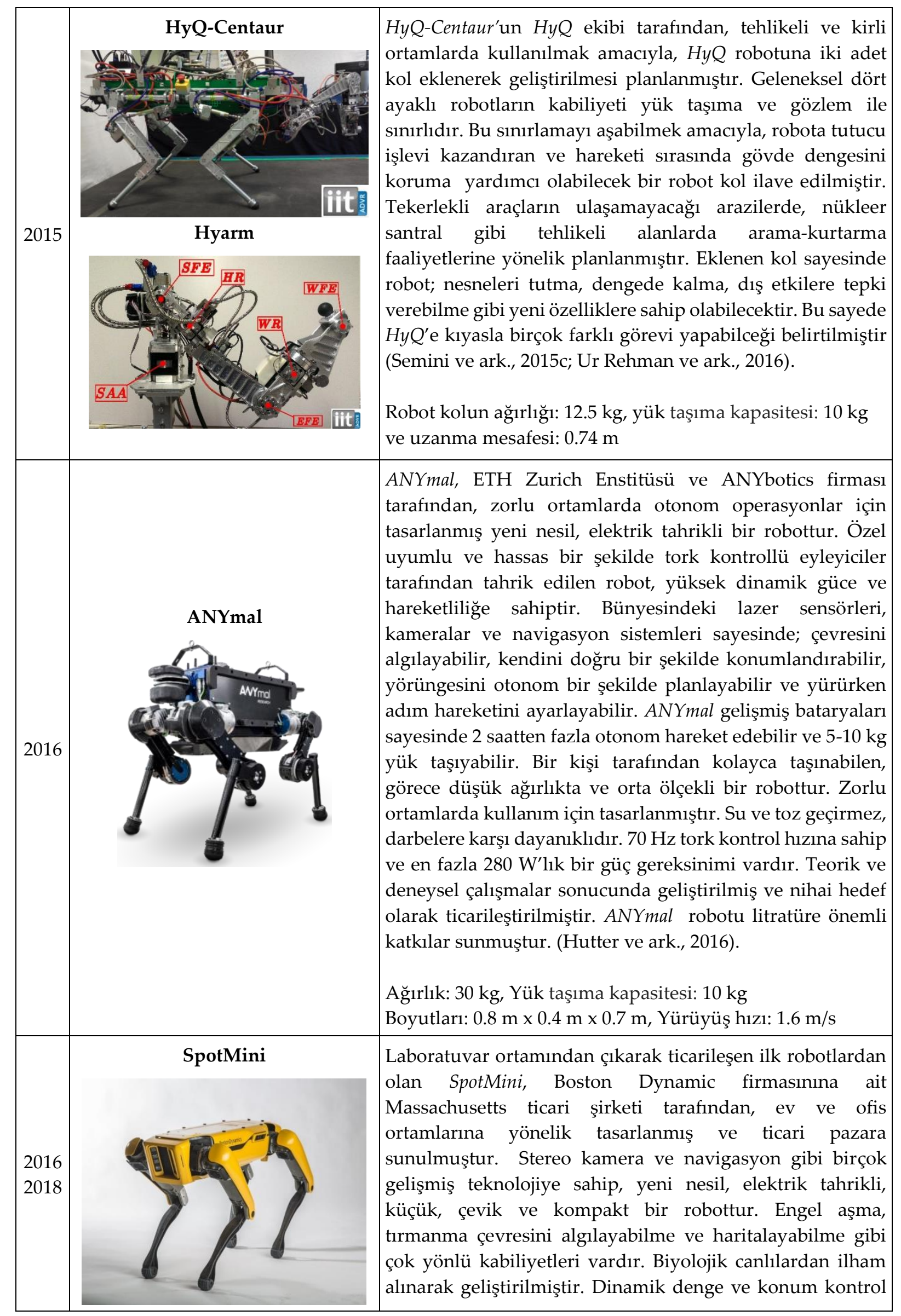




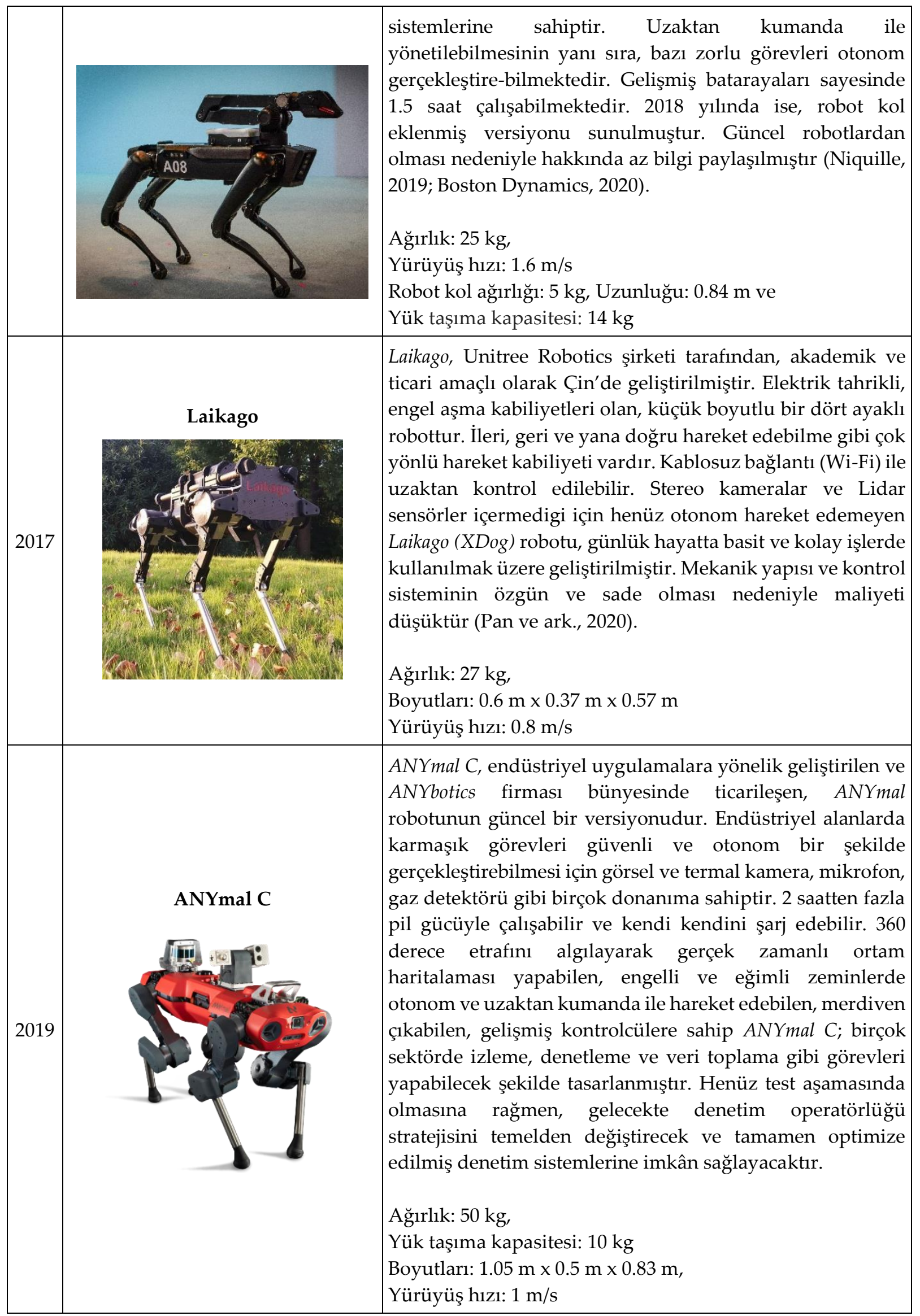




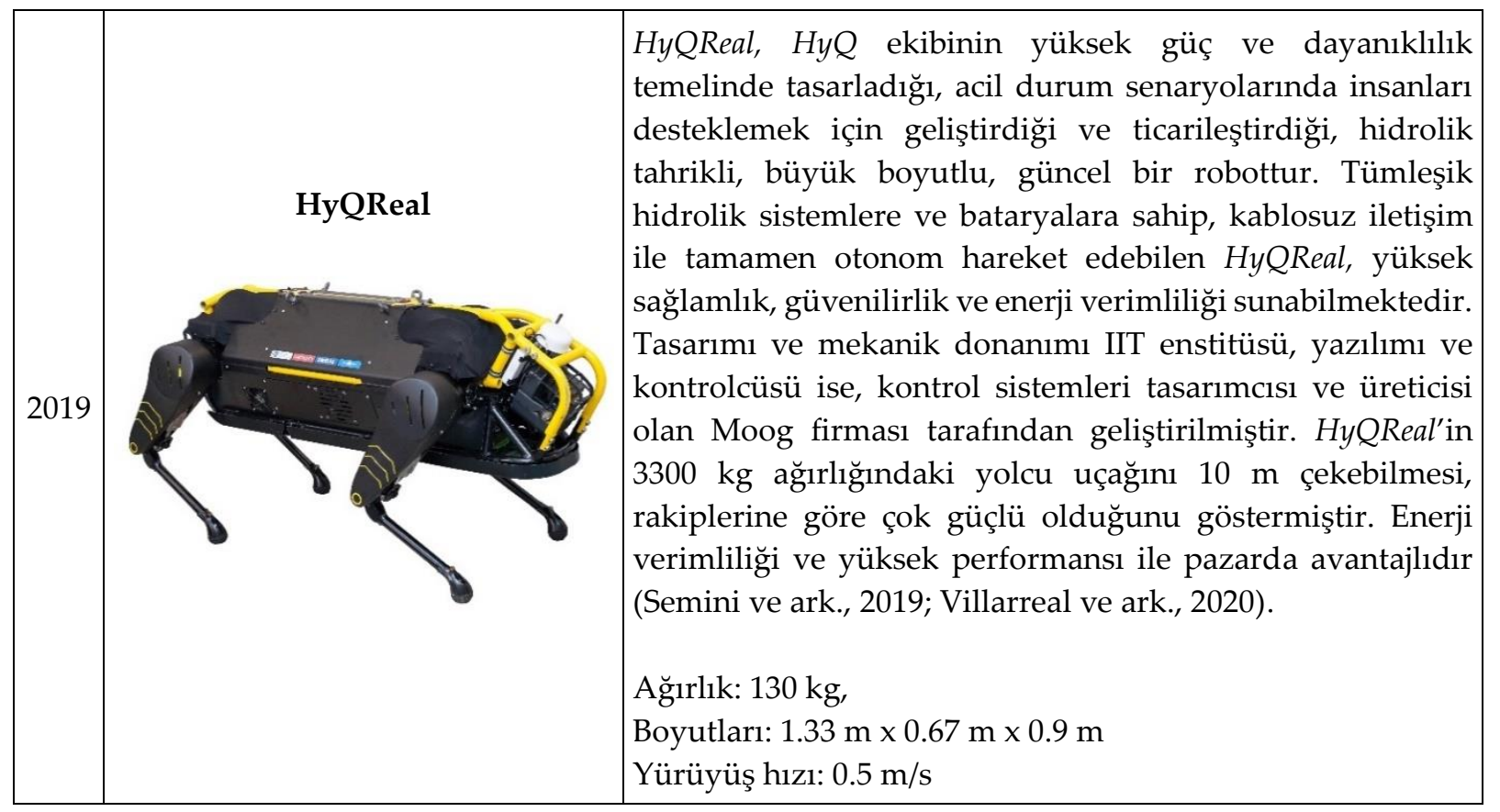

Yukarıda belirtilen güncel dört ayaklı robotlara bakıldığında; Boston Dynamics firması, İtalyan Teknoloji Enstitüsü ve ETH Zürich Enstitüsü olmak üzere, dünya çapında üç temel kurumun ön plana çıktığı görülmektedir. Robotların yapılarını, kullanım amaçlarını ve tarihsel sıralamalarını genel olarak incelediğimizde;

- Bacaklı robotik alanda öncü ve yönlendirici konumda olan ancak gizlilik nedeniyle çok az bilgi paylaşan, Amerikan ordusu destekli, M. Raibert liderliğindeki Boston Dynamics firması; yüksek yük taşıma ve dayanıklılık temelli, hidrolik tahrikli ve büyük boyutlu BigDog isimli robot ile başlattığı serüvenini; ev ve ofis ortamında basit görevleri insan ile etkileşimli olarak yapabilecek, elektrik tahrikli ve küçük boyutlu SpotMini isimli robot ile sürdürmektedir (Boston Dynamics, 2020).

- Akademik boyutta başlattıkları çalışmalar ile literatüre önemli kazanımlar sağlamanın yanı sıra, yakın zamanda ticarileşme yoluna giden C Semini liderliğindeki İtalyan Teknoloji (IIT) Enstitüsü; yüksek güç ve sağlamlık gerektiren zorlu işler için hidrolik tahrikli, büyük boyutlu robotlar geliştirmektedir. $\mathrm{HyQ}, H y \mathrm{Q} 2 \mathrm{Max}$ isimli robotların daha güçlü versiyonu olan, birçok sektörde ve

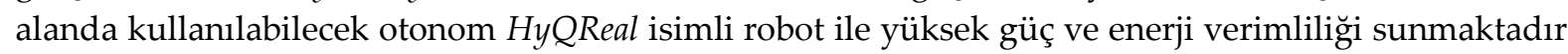
(Semini, 2010; Boaventura, 2013; Focchi, 2013; Khan, 2015; Mastalli, 2017; Orsolino, 2019).

- Benzer şeklide, M. Hutter liderliğindeki ETH Zurich Enstitüsü ise; fazla zorlu olmayan ancak karmaşık hareketleri gerçekleştirebilen, seri elastik elektrikli eyleyiciler ile tahrikli, küçük boyutlu, hızlı çevik StarlETH isimli robot ile literatürde önemli bir yere sahiptir. İlk robotları küçük boyutlarda olmasına rağmen, sonrasında güçlü ve dayanıklı ANYmal robot serisini geliştirmişler ve ANYbotics firmasını kurmuşlardır. Endüstriyel alanlarda denetim ve veri toplama gibi görevlere yönelik tasarladıkları, yüksek algılama ve çevresini haritalandırabilme kabiliyetlerine sahip otonom ANYmal C versiyonu geliştirmeyi sürdürmektedirler (Hutter, 2013; Bloesch, 2017; Gehring, 2017).

Günümüzde dört ayaklı robotlar ile ilgili çalışmalar; robotun tasarımı ve modellenmesinin yanı sıra, eklemlerin tork/kuvvet kontrolü ve gövdenin denge kontrolü, yürüyüş planlaması, ortam haritalaması ve engebeli yüzeylerde yürüyüş gibi ana başlıklar altında, teorik ve deneysel olarak sürdürülmektedir. 


\section{MODELLEME, KONTROL VE EYLEYİCILER (MODELING, CONTROL, AND ACTUATORS)}

İnsanların ve hayvanların yürüme, koşma gibi hareketleri, basit dinamik modeller üzerinden açıklanabilmektedir. Bunların en önemlilerinden biri olan doğrusal ters sarkaç modeli üzerinden, yürüyüş sırasında gövdenin hareketi ve dengelenmesi tam olarak ifade edilebilir (Winter, 1995). 1980 yıllarında M. Raibert tarafında geliştirilen Yay Eklenmiş Ters Sarkaç modeli (Spring-Loaded Inverted Pendulum, SLIP), rijit bir sarkaç modeline kıyasla koşma hareketini çok daha iyi temsil edebilmektedir (Alexander, 1990). SLIP yöntemi çok karmaşık sistemlere dahi uygulanabilmekte, basit modeller ve kontrol kuralları ile etkili çözümler sunabilmektedir.

Park ve ark. (2014) ise, dört ayaklı zıplamayı kontrol etmek için açısal momentumu da hesaba katan farklı bir model kullanmışlardır. SLIP modeli, robot bacağını noktasal bir kütle varsayarak, yay eklenmiş bir ters sarkaç sistemi olarak modeller. Yay, kütlenin ağırlık merkezini dengeleyerek hareket evreleri (uçuş ve destek evresi) arasındaki geçişte momentumu koruma işlevi görür. Uçuş evresinden destek evresine iniş açısı, gövdenin nasıl ivmeleneceğini belirler. Ters sarkaç dinamiklerinin kontrol edilmesiyle stabil bir hareket sağlanır. Bu yaklaşım her biri SLIP model formunda tasarlanmış birden çok bacağa sahip bir robot için de uygulanabilir. SLIP gibi mekanik modeller, karmaşık denklemlerin sayısal olarak çözülmesini gerektiren kompleks modellere kıyasla, daha basit çözümler sunabilir ve eğrisel formlarda tasarlanan temel ayak ucu yörüngeleri için hızlı sonuçlar verebilirler. Bu tür mekanik modeller, kontrol yöntemlerinin geliştirilmesi ve denge probleminin çözümü için bacaklı robotik alanındaki araştırmacılara ilham vermiştirler (Ubellacker, 2016). Şekil 8’ de SLIP modelinin hareketi şematik olarak gösterilmiştir.

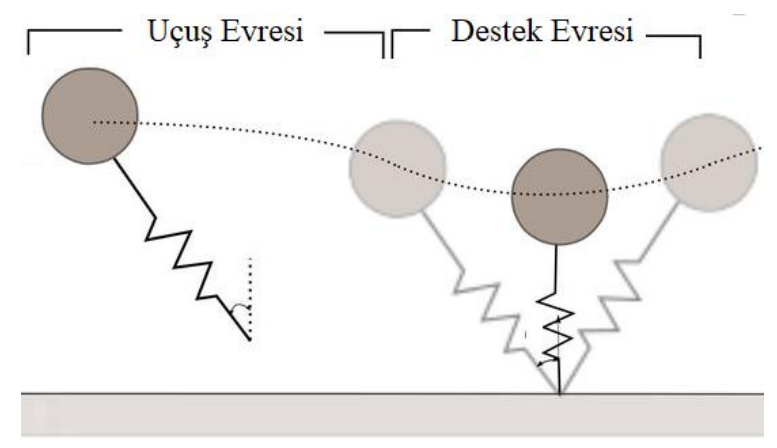

Şekil 8. Yay eklenmiş ters sarkaç modeli (SLIP)

Figure 8. Inverted pendulum with spring added (SLIP)

Robotlar; uzuvları genellikle rijit cisimler olarak modellenen, girişleri eyleyici torkları çıkışları ise eklemlere ait açısal konumlar olan sistemlerdir. Endüstriyel robotların tork/kuvvet kontrolü üzerine araştırmalar 1950'lere dayanır. Mafsallı robotların geliştirilmesiyle, tork kontrolü büyük ilgi odağı olmuştur (Whitney, 1985). Bacaklı robotik alanında ise, Raibert (1986)'ın düzlemsel zıplayan tek bacağın kontrolüne yönelik çalışmaları bir dönüm noktasıdır. Önerilen kontrol yönteminin iki temel bileşeni; kalça eklemi üzerinden gövde kontrolü ve ayak ucu pozisyon kontrolü ile dengenin sağlanmasıdır. Bu temel ve basit metot, iki ve dört ayaklı sistemler için de başarılı bir şekilde uygulanmıştır. Sonrasında, bacaklı sistemler için tork/kuvvet kontrol yöntemlerinin gelişimi devam etmiş ve son yıllarda yoğunlaşmaktadır.

Tork tabanlı kontrol, çeşitli empedans kontrol formlarında temas (kontak) kuvvetlerinin kontrolüne, rijit cisim dinamiği modeline dayalı kontrole ve diğer birçok model tabanlı kontrol uygulamalarına imkân verir. Yaygin olarak kullanılan empedans ve model tabanlı tork/kuvvet kontrol teknikleri mevcuttur.

N. Hogan tarafından sunulan çalışmaların, eklemli manipülatörlerin empedans kontrolü için temel olduğu düşünülmektedir (Hogan, 1985a; Hogan, 1985b). Hogan, dinamik etkileşim halindeki iki sistemin, birbirini fiziksel olarak tamamlaması gerektiğini vurgulamıştır. Robotun çevre ile fiziksel uyumunu sağlamak için genellikle, çevrenin giriş (admittance) kabul edildiği ve uç işlevcinin ise empedans davranışı gösterdiği yaklaşımlar kullanılmıştır. Genel olarak empedans kontrol, kartezyen koordinat sisteminde çevre tarafından uygulanan bir harekete cevap olarak üretilen kuvveti denetler ve istenilen dinamik 
kapasitif-sönüm-endüktif etkiye göre eklemlere uygulanacak torkları üretir. Kazerooni ve ark. (1986), sınırlı model belirsizlikleri için çok değişkenli Nyquist kriterlerini kullandıkları, çevre ile uyumu denetleme yönelik farklı bir yöntem sunmuşlardır. Albu-Schaffer ve Hirzinger (2002), eklem sertliklerinin kontrolünü dikkate alarak, gelişmiş bir empedans denetleyici yapısı önermişlerdir. Bu yapı, Hogan'ın önerdiği klasik yönteme göre daha iyi bir empedans kontrol performansı sağlayabilmesine karşın daha düşük geometrik doğruluk göstermiştir.

O. Khatib, hareket ve kuvvet kontrolünü birlikte ele alarak, Operasyonel Alan Kontrolü (Operational Space Control-OSC) kavramı ve formülasyonları ile farklı bir yaklaşım sunmuştur. Eklemlerin kontrolünden daha çok robota verilen göreve, yani uç işlevcinin performansına odaklanan bir yaklaşım önermiştir (Khatib, 1987). Bu yaklaşımda, uç işlevcinin hem konumunun hem de temas kuvvetlerinin kontrolü, eklem torklarının denetimine dayanır.

Bacaklı hareket kontrolü için Pratt ve ark. (2001) sezgisel tabanlı Sanal Model Kontrolü (Virtual Model Control) tekniğini önermişlerdir. Bu teknikte; yay, damper gibi mekanik parçalar ile fiziksel olarak eşdeğer sanal bileşenler, robotun içine veya robot ile çevre arasındaki uygun konumlara tanımlanır. Daha sonra, bu sanal bileşenler ile robotun etkileşimi, eyleyicilerden istenen torkları ve kuvvetleri üreten Jacobian matrisi ile ifade edilir. Şekil 9a'da, sanal model kontrolü yöntemiyle geliştirilmiş yürüyüş mekanizması verilmiştir. Diğer model tabanlı yaklaşımlarda ise, genellikle rijit cisim dinamiği tabanlı matematiksel modeller kullanmıştır. Buchli ve ark. (2009), bacaklı hareket kontrolünün gürbüzlügünü artırmaya yönelik, rijit cisimler için model tabanlı ve ters dinamik kontrole dayalı bir çözüm sunmuşlardır. Bu yöntem, yörünge takibinde önemli bir kayba sebep olmaksızın pozisyon geri besleme kazancının azaltılmasına imkân verir. Bu düşük geri besleme kazançları sayesinde, robot bilinmeyen muhtemel engebeli arazide daha gürbüz ve kararlı hareket edebilir. Mistry ve ark. (2010), kayan nokta (floating base) tabanlı koordinat sistemine sahip robotların, noktasal temasların dinamik olarak sürekli değişmesinden kaynaklı sorunların üstesinden gelmek için, rijit cismin ters dinamiğini hesaplayan bir ortogonal ayrışma yöntemi önermişlerdir. Kayan nokta tabanlı bir sistemde, robot gövdesine ait (body frame) koordinat sistemi ve temel (inertial frame) koordinat sistemi Şekil 9b'de görülmektedir.

a)

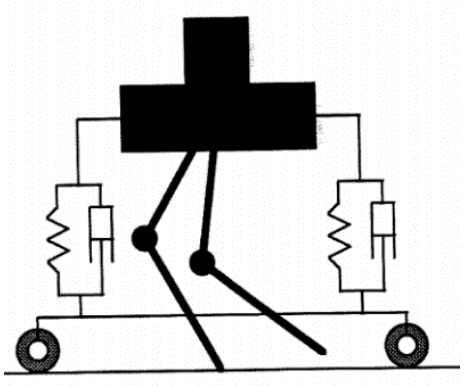

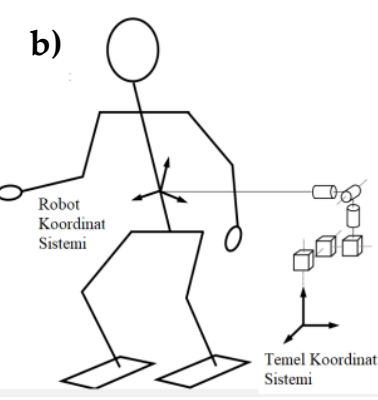

Şekil 9. a) Sanal model kontrollü yürüyüş mekanizması b) Kayan nokta tabanlı robot modeli Figure 9. a) Virtual model controlled walking mechanism b) Floating point based robot model

Kuvvet kontrolü gerektiren sistemlerde eyleyicilerin güç aktarımdaki sertlik, denge ve kararsızlık problemlerinin ana nedenidir. Ayrıca, eyleyicilerin çalışma frekanslarının sınırlı olması ve yetersiz sayısal hesaplama hızı nedeniyle oluşan gecikmeler, kapalı çevrim kontrol sistemlerinin kararlılı̆̆ını olumsuz etkilemektedir (Whitney, 1985). Bu tür sorunların üstesinden gelmek için, eyleyicilere esnek yaylar eklenerek aktarım sertliğinin azaltılması sağlanmıştır (Pratt ve Williamson, 1995).

Seri Elastik Eyleyicilerin (Series Elastic Actuators-SEA), aktarım sertliğini azaltmanın yanı sıra, darbe kuvvetlerinden kaynaklanan hasarları önlemek, enerji depolamak, daha güvenli bir insan/çevre ve robot etkileşimi sağlamak gibi özellikleri vardır. SEA'ların tasarımı, sağlamlık ve performans arasında bir denge kurulmasını gerektirir. Robotun çok yönlü hareket kabiliyeti açısından uygun yay sertliğini seçmek önemlidir. Yüksek eklem sertliği istenmediği gibi, düşük eklem sertliği ise robotun kontrol edilebilirliğini ve ayak ucu yörünge izleme yeteneğini düşürmektedir. Bu sebeple, Grebenstein ve ark. (2011) ve Tsagarakis ve ark. (2011), ayarlanabilir değişken sertlik değerlerine sahip farklı SEA tasarımları ve çalışma 
prensipleri önermişlerdir. Değişken sertliğe sahip eyleyiciler önemli çözümler sunabilmelerine karşın ağırlık, hacim, mekanik karmaşıklık, düşük sağlamlık ve hız gibi özellikleri nedeniyle yüksek dinamik hareketli robotlar için yetersiz kalmaktadır. Kuvvet, eyleyiciden yüke sonlu sertliğe (rijit olmayan) sahip hidrolik akışkan veya yay ile aktarıldığından dolayı yükün hızı geri beslenir. Gelişmiş model tabanlı kontrol teknikleri, bu geri beslemeyi telafi etmek üzerine tasarlanmaktadır (Boaventura ve ark., 2012a).

M. Hutter ve ekibi, geliştirdikleri StarlETH (Hutter, 2013) ve ANYmal (Hutter ve ark., 2016) isimli elektrik tahrikli robotların; tasarımlarını, eyleyici dinamiğinin ayrıntılı modelini, mekanik analizlerini ve düşük seviye kontrol tekniğini (low-level controller) detaylı olarak sunmuşlardır. Yüksek verimli ve zıplama/koşma gibi çok yönlü hareketlere uyumlu, insan/hayvan bacak yapılarından ilham alınarak tasarlanan, iki uzuvlu StarlETH robotuna ait bacak yapısını ve aktif sönümleme içeren entegre bir eklemlerin tork, pozisyon kontrolüne yönelik bir yaklaşım tanıtmışlar, detaylı analizler sunmuşlardır (Hutter ve ark., 2012b; Hutter ve ark., 2013). Güçlü bir öğrenme metodu kullanarak (reinforcement learning), StarlETH robotunun optimal tek-bacak zıplama hareketinin kontrolünü gerçekleştirmişlerdir (Fankhauser ve ark., 2013). Önerilen tek-bacak zıplama kontrol tekniğinin, yüksek hizlardaki sürtünme etkisinde yetersiz kaldığını ve büyük güç gereksinimlerini karşılamadığını belirtmişlerdir (Heijnen, 2014). Eklem kinematiği ile ters dinamik operasyonel alan kontrolünün birleşiminden oluşan hibrit bir operasyonel alan kontrolcü geliştirmişler ve StarlETH robotuna başarıyla uygulamışlardır (Hutter ve ark., 2014). Büyük adımlar ile robotun çevresini görmeden/haritalandırmadan kör yürüyüşüne yönelik (blind walking) hiyerarşik bir optimizasyon formüle etmişlerdir (Bellicoso ve ark., 2016). Robotun daha hızlı ve düşük enerji tüketimine yönelik modelleme, yürüyüş planlaması ve gürbüz bir model tabanlı kontrolcü sunmuşlardır (Gehring, 2017). Fankhauser ve Hutter (2018), yüksek hareketliliğe ve çok yönlülüğe sahip dört ayaklı robotlar için, klasik mekanik dişli sistemine sahip eyleyicilerin kullanılamayacağını, klasik eyleyicilerin sadece yavaş ve statik hareketler üretebileceğini belirtmişlerdir. Eklem torkunu, pozisyonunu ve empedansını herhangi bir ek bileşene gerek kalmadan doğrudan düzenleyebilen, kompakt ve küçük boyutlu, ANYdrive isimli bir yeni nesil SEA sunmuşlar ve geliştirdikleri ANYmal isimli robotta kullanmışlardır. Grandia ve ark. (2019) bacaklı robotlar için daha gürbüz kontrol çözümleri geliştirmek amacıyla, eyleyicilerin performans sınırları ile yürüyüş planlarını uyumlu hale getiren, frekans tabanlı, ayarlanabilir bir model öngörücü (model predictive) kontrol önermişler ve uygulamışlardır. Deneysel sonuçların ANYmal robotunun hareket ve tork performansını iyileştirdiğini ve önceden tanımlanmamış zeminlerde daha kararlı yürüyüş sağlayabildiğini bildirmişlerdir. Şekil 10'da, StarlETH ve ANYmal robotları için geliştirilen elektrikli eyleyiciler ve bacak yapıları verilmiştir.
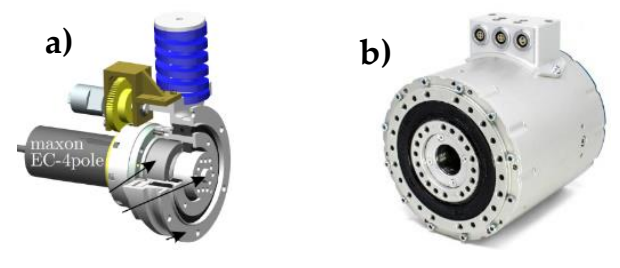

c)

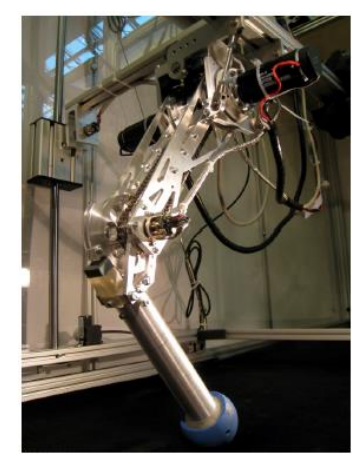

d)

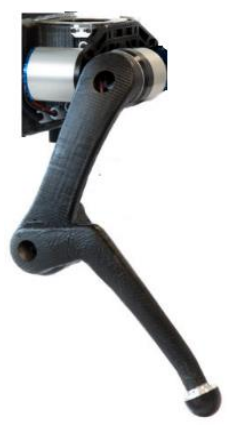

Şekil 10. ETH Zürih'te geliştirilen a),c) StarlETH ve b),d) ANYmal robotlarına ait eyleyiciler ve bacak yapıları Figure 10. Actuators and leg structures of $\boldsymbol{a})$, c) StarlETH and $\boldsymbol{b}$ ), d) ANYmal robots developed at the ETH Zurich

C. Semini ve ekibi, geliştirdikleri $H y Q$ (Semini, 2010), HyQ2Max (Semini ve ark., 2015c) ve HyQ-Real (Semini ve ark., 2019) isimli hidrolik tahrikli robotların; tasarımlarını, hidrolik eyleyicilerinin analizlerini ve geliştirilen kontrolcülerini kapsamlı olarak sunmuşlardır. Çalışmalarına, düşey bir kızak üzerine doğrusal hareketli olarak sabitlenmiş, iki uzuvlu, $\mathrm{Hy}$ isimli bir hidrolik robot bacağın geliştirilmesi ve kontrolü ile başlamışlardır. Başlangıçta, sistemin denge problemi olmadığı için, öncelikle eklemlerin kuvvet ve pozisyon kontrolü üzerinde durmuşlardır. Eklemlerin açısal konumlarının ölçümünde enkoder kullanmışlar ve 
bu sayede bacağın pozisyonunu tayin etmişlerdir. İlk olarak, benzetim ve uygulama çalışmaları için gerçek zamanlı bir kontrol yazılımı (Schaal, 2009) kullanmışlardır. Koşma ve zıplama gibi oldukça dinamik hareketlere uyumlu bu bacak yapısı birçok kontrol tekniklerinin test edilmesine ve analizine imkân sağlamıştır. Semini ve ark. (2008), bacak yapısının fiziksel parametrelerini ve test sisteminin kurulumunu açıklamış, bacağın zıplama hareketine ait deneysel sonuçları, analizleri rapor etmişlerdir. Yüksek güç ve hızlı bir dinamik tepki sunabilmesi nedeniyle hidrolik eyleyiciler tercih edilmiş, performans ve fiziksel boyutlar açısından elektrikli eyleyiciler ile karşılaştırılması yapılmıştır. Cunha ve ark. (2009) bacağın ilk kontrol yaklaşımı olarak, kazançlarının yürüyüş döngüsüne ve eklem konumuna göre ayarlanabildiği bir PID kontrol algoritması uygulamışlardır. Semini ve ark. (2011), HyQ robotunun tasarım yapısı, hidrolik eyleyici ve kontrolcü bileşenleri hakkında detaylı bilgiler vermişlerdir. $H y Q$ robotu, aktif uyumlu kontrol sağlayan, tam tork kontrolcüye sahiptir (Boaventura ve ark., 2012b; Boaventura ve ark., 2013). Ugurlu ve ark. (2013) hidrolik tahrikli robotlarda dinamik ve uygulanabilir yürüyüş hareketi üretmek için birleştirilmiş bir yörünge sentezleyici ve aktif kontrol şeması önermişler, HyQ robotunda uygulamışlardır. Semini ve ark. (2015a), yay gibi pasif elemanların aksine gerçek zamanlı eklem sertliği ve sönümleme ayarı sağlayan, tork kontrol tabanlı aktif bir empedans kontrolcü önerilmişler ve HyQ robotun yürüyüşündeki etkisini değerlendirmişlerdir. Focchi ve ark. (2016) empedans sertlik ve sönüm parametrelerinin etkisi üzerine deneysel ve benzetim çalışmaları ile kapsamlı bir analiz çalışması sunmuşlardır. Koivumäki ve ark. (2017) hidrolik bacak kontrolü için sanal ayrışma kontrol (Virtual Decomposition Control-VDC) yaklaşımı ile doğrusal olmayan model tabanlı bir kontrol tekniği sunmuşlardır. Semini ve ark. (2017) çalışmalarıyla, $H y Q$ robotuna göre daha sağlam ve güçlü olması amaçlanan, mevcut hareket kabiliyetini genişletmek amacıyla farklı kinematik yapıda tasarlanan bacak yapısına ve optimize edilmiş hidrolik mekanizmalara sahip HyQ2Max isimli versiyonu geliştirmişlerdir. Önerilen yeni tasarımın ve tork kontrolcünün, robotun önceki versiyonlarına kıyasla, farklı yüksek dinamikteki hareketleri gerçekleştirmedeki performansını araştırmak için deneysel ve simülasyon çalışmaları yapmışlar, detaylı analizler sunmuşlardır. Barasuol ve ark. (2018), HyQ-REAL robot bacağında kullanılmak üzere; yüksek güç, sağlamlık ve geniş çalışma frekansı sunan, hidrolik silindir, servo valf ve elektronik bileşenlerden oluşan, basınç/konum/sıcaklık algılayıcıları sayesinde aktif empedans ve kuvvet kontrolüne uygun, hidrolik bir Entegre Akıllı Eyleyici (Integrated Smart Actuator-ISA) geliştirmişlerdir. Önerilen akıllı eyleyicinin dinamik modelini ve tasarladıkları kontrol mimarisini tanıtmışlar, tek bacak yapısı üzerinde deneysel olarak doğrulama çalışmaları ve değerlendirmeler sunmuşlardır. Bu eyleyicinin, robot ile yüksek oranda entegre edilmiş, bu alanda geliştirilen ilk hidrolik akıllı eyleyici olduğunu bildirmişlerdir. Şekil 11'de, $H y Q$ ve $H y Q-R E A L$ robotları için geliştirilen hidrolik eyleyiciler ve bu robotların bacak yapılarına ait görseller sunulmuştur.
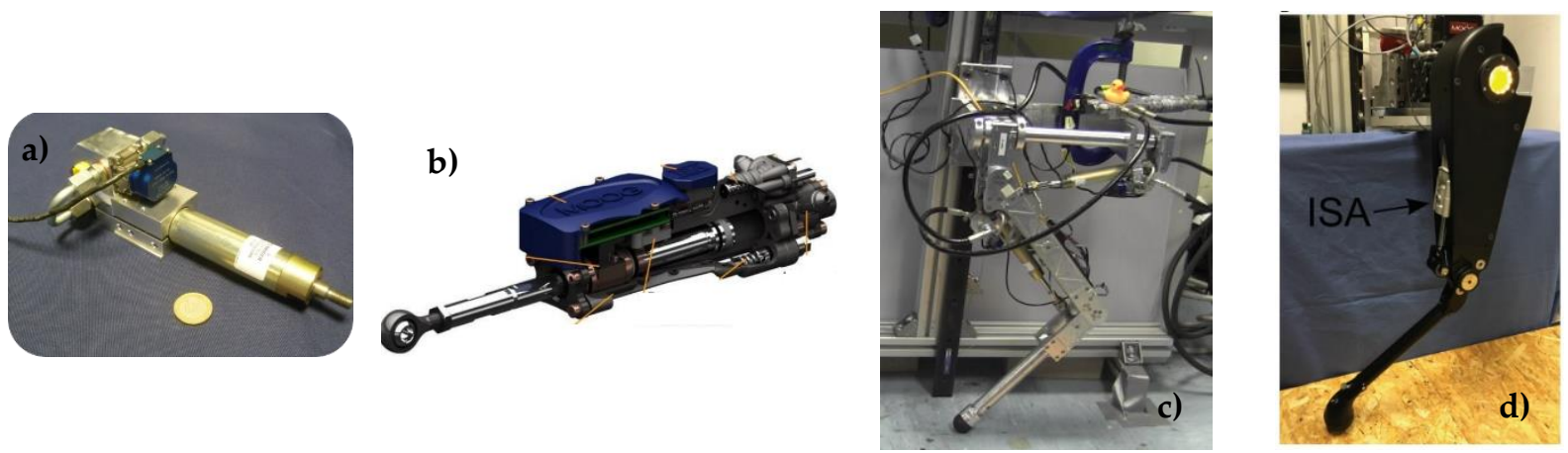

Şekil 11. IIT Enst. geliştirilen a),c) HyQ ve b),d) HyQ-REAL robotlarına ait eyleyiciler ve bacak yapıları Figure 11. Actuators and leg structures of $\boldsymbol{a}), \boldsymbol{c}) \mathrm{HyQ}$ and $\boldsymbol{b}), \boldsymbol{d}) \mathrm{HyQ}-\mathrm{REAL}$ robots developed at the Italian IIT Institute

Hoffmann ve Simanek (2017), geliştirdikleri dört ayaklı bir robotun diz eklemlerine yay ekleyerek aktif/pasif eklem (Active/Passive Compliant Joint) oluşturup, deneysel ve benzetim çalışmaları gerçekleştirmişlerdir. Yay eklenerek oluşturulan eklem yapısının; yürüyüş algoritmasının öğretilmesi, enerji verimliliği ve ölçüm alma üzerine etkileri, avantajları incelenmiştir. Pasif eklem yapısının, düz zeminlerde aktif eklem yapısına kıyasla, robotun \%30 50 oranında daha stabil ve verimli bir yürüyüş 
gerçekleştirebildiği sonucuna varılmıştır. Ayrıca, pasif eklemin işlevsel ve ucuz olmasının yanı sıra, arazi şartlarına daha iyi uyum sağlayabildiği belirtilmiştir. Önerilen eklem yapısının, hassas kontrol gerektirmeyen uygulamalarda, karmaşık yapının, maliyetin ve toplam ağırlığın azaltılması; enerji verimliliğinin ve güvenilirliğin artırılması açısından avantajları olduğu ifade edilmiştir (Şekil 12a).

Lei ve ark. (2017), çitanın biyolojik anatomisinden ve kas yapısından esinlenerek, pnömatik yapay kaslarla çalışan, hafif ve esnek bir biyonik bacak geliştirmişlerdir. Sistemin jakobiyen matrisi ve kinematik çözümlemeleri yapılmıştır. Bacağın yüksek hızda hareketi ve yumuşak teması için, ayak temas kuvvetlerine göre ayak esnekliğine bağlı potansiyel enerjisi analiz edilmiş ve ayağın katılığını veren bir model sunulmuştur. Önerilen bacak modeli deneysel çalışmalar ile doğrulanmıştır (Şekil 12b).

Kitano ve ark. (2016), yüksek hızlı ve enerji tüketimi açısından verimli bir yürüme yeteneğine ve genişleyen tipte (sprawling-type) bacak yapısına sahip TITAN-XIII isimli bir dört ayaklı robot geliştirmişlerdir. Bu robot, geniş bir ayak destek poligonu ve hafif gövde ağırlığı sayesinde yüksek kararlılığa sahiptir. Yürüme hızını ve enerji verimliliğini artırmak için hafif ve kompakt bir bacak yapısı tasarlamışlar ve yürüme hızını $1.38 \mathrm{~m} / \mathrm{s}$ hıza kadar artırmışlardır. Böylece, örümceğe benzer bir yapıda geliştirilmiş ancak, memeli hayvan yapısındaki bir robot ile ayn hız ve enerji verimliliğine sahip olabileceğini belirtmişlerdir.
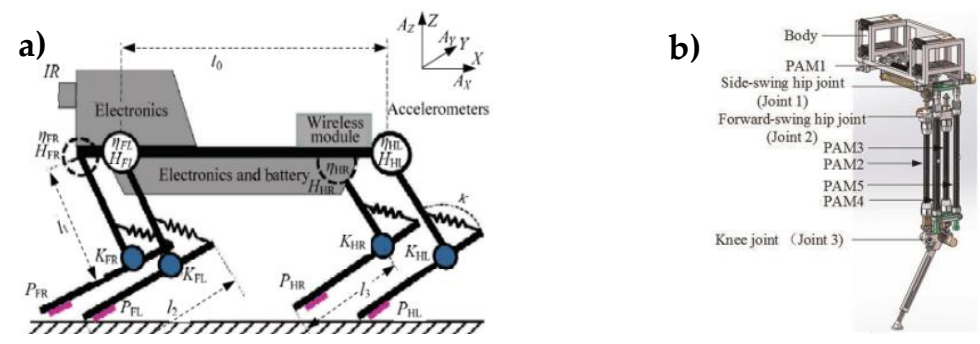

Şekil 12. a) Aktif/pasif eklem yapısına sahip model b) Pnömatik tahrikli biyonik Figure 12.a) Model with active / passive joint structure b) Pneumatic driven bionic

\section{ENGEBELI YÜZEYLERDE YÜRÜYÜŞ KONTROLÜ VE SIMÜLASYON ÇALIŞMALARI (GAIT CONTROL AND SIMULATION STUDIES ON ROUGH SURFACES}

Bacaklı sistemlerin en önemli avantajları, zorlu arazi şartlarındaki yüksek hareketlilik sağlayabilme potansiyelleridir. Ancak engebeli arazi koşullarına yönelik tüm gövde hareket planlanmasının ve kontrolünün karmaşıklığı, dört bacaklı robotların hareketliliğini düz araziler ile sınırlamaktadır. DARPA'nın yürüyüş öğrenme programı kapsamında gerçekleştirilen, LittleDog isimli küçük boyutlu robotun engebeli, düzensiz bir zemindeki yürüyüş çalışması, bu alandaki diğer araştırmalara yön vermiştir. Bu çalışmada Rebula ve ark. (2007), robotun engebeli arazide statik yürüyüşü için kaymayı, çarpmayı ihmal eden reaktif bir kontrolcü geliştirmişlerdir. Önceden tasarlanmış küçük boyutlardaki engebeleri aşmak için geliştirilen bu kontrolcü, birden fazla yürüyüş modeline ve bunlar arasında geçişe uygundur. Bu sayede, robot $7.5 \mathrm{~cm}$ (bacak uzunluğunun \% 40'1) engebelerden geçebilmektedir (Şekil 13).

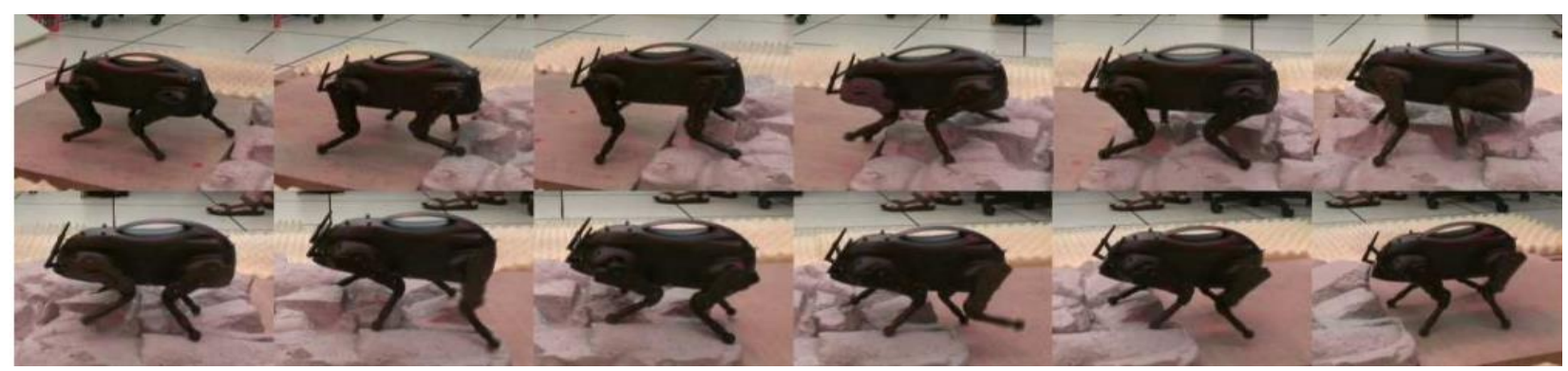

Şekil 13. LittleDog robotunun engebeli zeminde yürüyüşü Figure 13. LittleDog robot walking on rough/uneven ground 
Literatürde, engebeli arazide hızlı ve sağlam bir yürüyüş için önerilen farklı hareket planlama ve kontrol yöntemleri mevcuttur. Kalakrishnan ve ark. (2011), üç ana alt sistemden oluşan, temel bir hiyerarşik yaklaşım önermişlerdir. Bu yaklaşım; gövde duruş planlayıcısı, adım hareket planlayıcısı ve kayan nokta tabanlı ters dinamik kontrolcüden oluşmaktadır. Bu hiyerarşik ayrışmanın en önemli avantajı, hesaplama süresini azaltmasıdır. Focchi ve ark. (2013), robotun yüzeydeki düzensizlikleri bilmediği ve görsel bir geri bildirim alamadığı durumlarda, ayak ucu reaksiyonu tepki hızının çok önemli olduğunu bildirmişler ve $H y Q$ robotunun reaktif olarak yüksek engelleri (Şekil 14a) aşabilmesi için yerel bir refleks yöntemi önermişlerdir. Benzer şekilde, Barasuol ve ark. (2013), eğimli ve düzensiz zeminlerde gürbüz bir yürüyüş sağlamak amacıyla, gövdenin duruşunu da dikkate alarak, eliptik ayak ucu yörüngeleri üreten Merkezi Örüntü Üretimi (CPG) tabanlı bir reaktif kontrol algoritması önermişleridir (Şekil 14b).
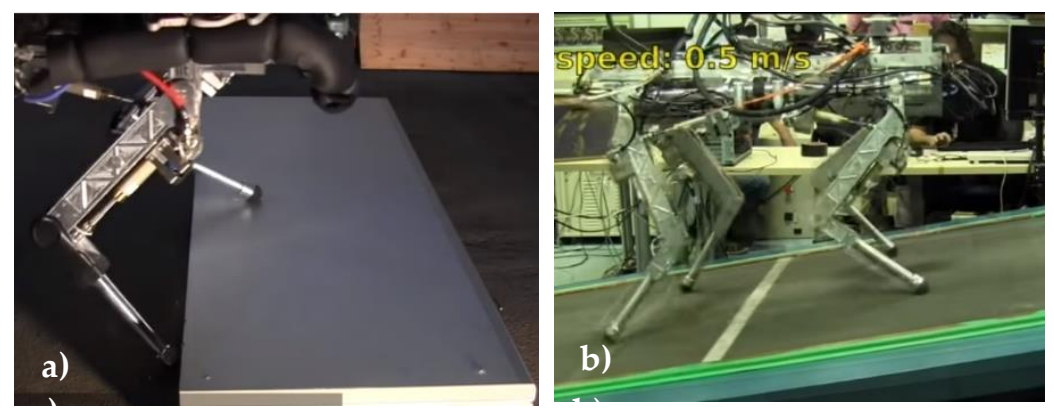

Şekil 14. HyQ robotunun ayak ucu reaktif yöntem ile a) basamak aşması ve b) eğimli zeminde hareketi Figure 14. The movement of the $H y Q$ robot with foot-end reactive method $\boldsymbol{a}$ ) stepping on steps and $\boldsymbol{b}$ ) sloping ground

Gehring ve ark. (2013), StarlETH isimli robotun farklı yürüyüş çeşitleri ve farklı hızlarda yürüyüşü için esnek bir kontrol algoritmasını geliştirmişler ve deneysel olarak doğrulamışlardır. Önerilen algoritmanın, yürüyüş çeşitleri arasında geçişlere izin verebildiğini ve beklenmedik arazi şartlarına göre parametrelerinin ayarlanabilir olduğunu bildirmişlerdir. Robotun yürüyüş sırasında $5 \mathrm{~cm}$ yüksekliğindeki üç boyutlu engebeleri aşabildiğini belirtmişlerdir (Şekil 15a). Wagner ve ark. (2017), zeminine ait teğetsel tepki kuvvetlerini en aza indirmek ve kayma riskini azaltmak amacıyla, ayak ucuna yerleştirilen bir kuvvet sensörü ile temas kuvvetlerini tahmin etmeye dayalı bir yöntem önermişler ve doğrulamışlarıdır. Optik bir kuvvet sensörü modellemişler ve Kalman filtresi kullanılarak elde edilen eklem tork ölçümleri ile entegre edilmişlerdir. (Şekil 15b).
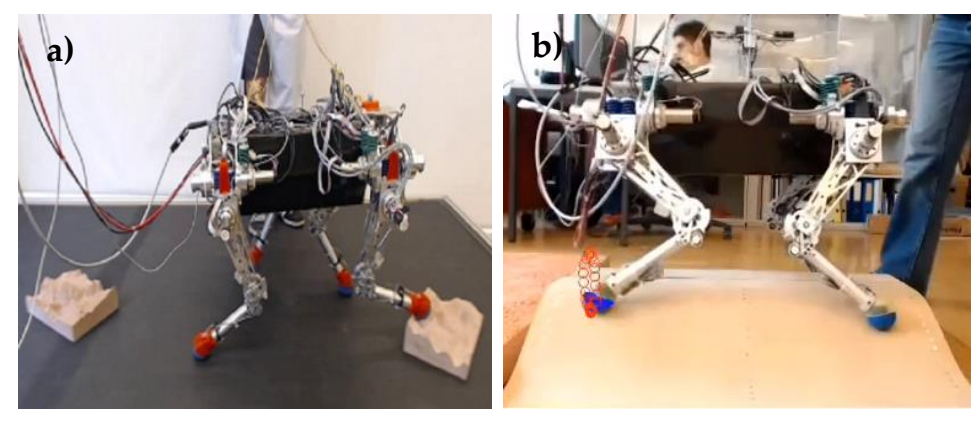

Şekil 15. StarlETH robotunun temas kuvvetlerine dayalı a) engebeli ve b) eğimli zeminlerde hareketi Figure 15. Movement of StarlETH robot based on contact forces on $\boldsymbol{a}$ ) uneven and $\boldsymbol{b}$ ) sloping ground

Winkler ve ark. (2014) zorlu arazi şartları için, ayak ucu tepki kuvvetlerine göre kendini güncelleyebilen, sanal model tabanlı tork bir kontrolcü kullanan, gürbüz ve esnek bir ayak ucu yörünge planlayıcısı önermişlerdir (Şekil 16a). Daha sonra, Winkler ve ark. (2015) tepki kuvvetleri yerine, online ortam modellemesi üzerinden yörünge güncellemesi yapabilen, sanal modelini ve sistem dinamiklerini birlikte dikkate alan, ZMP denge kriterine dayalı, daha hızlı bir yöntem önermişlerdir. (Şekil 16b). 

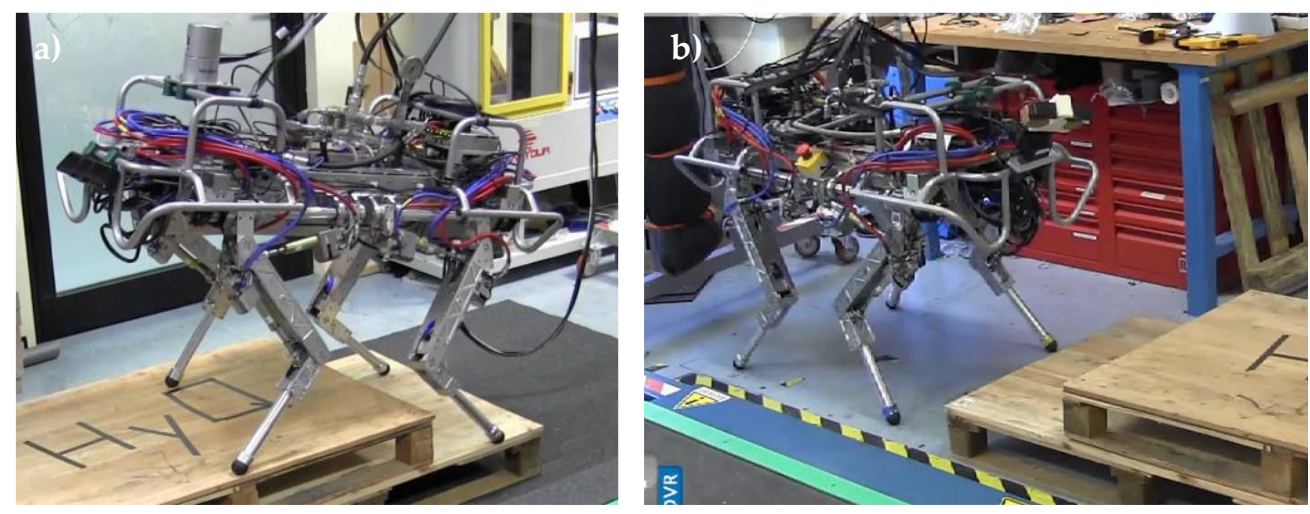

Şekil 16. $H y Q$ robotunun a) tepki kuvvetleri ve b) adım yörüngesinin güncellenmesi temelli hareketi Figure 16. Movement of the HyQ robot based on $\boldsymbol{a})$ reaction forces and $\boldsymbol{b}$ ) updating the step trajectory.

Focchi ve ark. (2017), HyQ robotun 'V' şeklinde 50 derece eğimli bir kanalın ortasında yarı-statik yürüyüş planlaması ve kontrolü üzerine bir çalışma gerçekleştirmişlerdir. Robotun ağırlık merkezinin denge kontrolü; ayağa etki eden kuvvetlere göre, gövde ağırlığının o anda zemin ile temas halindeki ayaklara dağıtılmasıyla sağlanmıştır. Bunun için, eklem torklarını ayakların kaymasını önleyecek şekilde hesaplayabilen Kuadratik Programlama tabanlı bir metot kullanmışlar ve önerdikleri yöntemi deneysel olarak doğrulamışlardır.

Mastalli (2017) ve Mastalli ve ark. (2020), robot dinamiklerini ve arazi modellemeyi uygun bir formülasyonda birleştirerek, ayak ucu yörünge ve gövde hareket planlaması (coupled planner) için yeni bir optimizasyon metodu önermişlerdir. Önerilen yöntemde, yürüyüş sırasında eş zamanlı arazi haritalaması ile elde edilen arazi topolojisi dikkate alınarak; gövdenin hareketi, ayağın temas noktaları ve adım süresi birlikte optimize etmişlerdir. Adım evrelerinin sürelerini ve gövdenin duruşunu ayarlayarak, robot yürüyüşünün araziye uyumunu artırmışlardır. Online arazi verisi kullanan gerçek zamanlı tüm gövde kontrolcüsü ve parametrik olarak ifade edilmiş dinamik model sayesinde, robotun farklı arazi koşularına kolayca uyum sağlayabileceğini belirtmişlerdir. Önerilen yöntem, $H y Q$ robotunun artan zorluk seviyelerindeki karmaşık zeminlerde yürüyüşü için gerçekleştirilen deneysel ve gerçekçi simülasyon çalışmaları ile doğrulanmıştır. Engebeli araziler için yürüyüş zamanlamasını otomatik ayarlayan ilk yaklaşım olduğu belirtilmiştir. (Şekil 17a).

Fankhauser ve ark. (2018), dört ayaklı robotların engebeli arazilerde hareketliliği için gürbüz bir hareket planlayıcısı sunmuşlardır. Online arazi haritalaması kullanılarak, ayak havada (uçuş evresinde) iken ayak ucunun herhangi bir yere çarpmadan güvenli bir basma noktası bulması ve robotun engelleri aşmasını sağlayacak yeni bir gövde duruş optimizasyonu amaçlamışlardır. Önerilen yöntemin doğruluğu, ANYmal robotu üzerinde test edilmiş ve robot eğim, basamak ve merdiven gibi engelleri otonom şekilde geçmeyi başarmıştır. Değişen arazi şartları ve bozucu giriş durumunda hareket planlayıcısı, hareketi her adımda tekrar planlamaktadır. Robotun ortam hakkında önceden bir bilgisi yoktur ve ortam haritalamasını, gövde duruş kontrolünü, yürüyüş planlamasını gerçek zamanlı gerçekleştirmektedir. Birbiriyle bağlantılı birkaç modülden oluşan yöntem, belirli bir duruş pozisyonu veya hız girişi ile başlar, mesafe sensörleri ve stereo kameralar ile sürekli ölçümler yaparak elde ettiği yükselti bilgileri ve arazi haritası sayesinde pozisyon tahmini yaparak bir sonraki duruş pozisyonu hesaplayabilmektedir. Gerçek zamanlı haritalama verileri ile, her ayağın adım atacağı yerin güvenilirliğini yansıtan bir uygunluk değeri hesaplanır. Hareket planlayıcının nihai çıkışı, ayak ucunun basacağı güvenli bir nokta ve bir sonraki adım hareketidir. Bu şekilde gövdenin mevcut pozisyonu ve hedef pozisyonu dikkate alınarak düzlemsel ayak temas noktaları üretilir. Bu ayak temas noktalarını gerçekleştirebilecek, kinematik ve denge kısıtlarına uygun, kararlı bir robot konfigürasyonunun bulunup bulunmadığını kontrol etmek için bir pozisyon denetleyicisi kullanılır. Önerilen hareket planlayıcısı, her bir bacak için her bir adımda tekrar hesaplatılır. Robotun genel hareket kontrolü, tüm gövde kontrolcüsü ile gerçekleştirilir (Şekil 17b). 

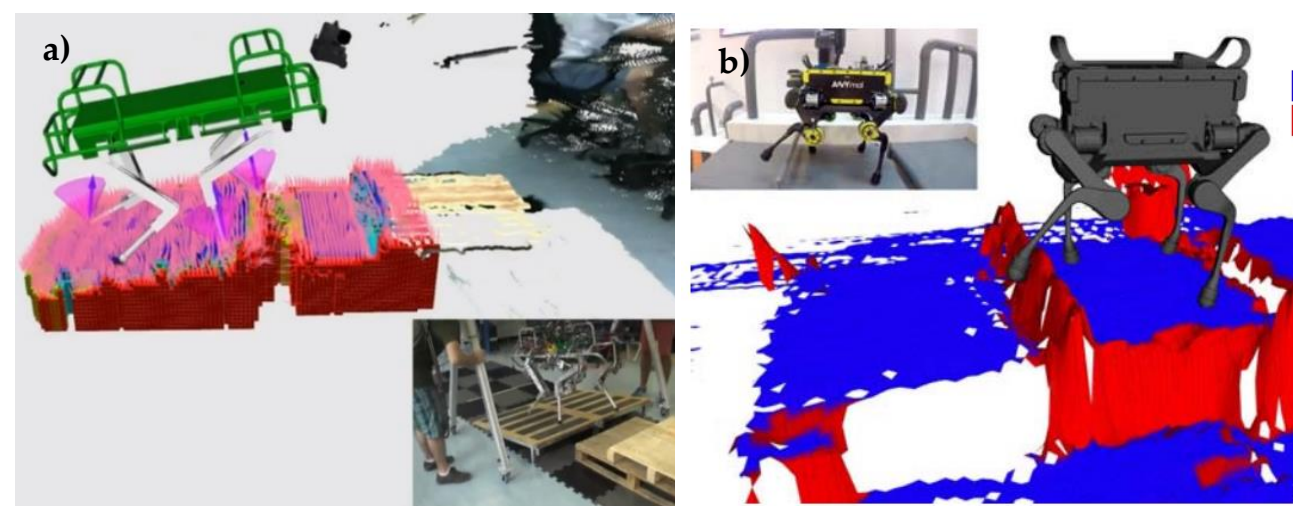

Şekil 17. a) $H y Q$ ve b) $A N Y$ mal robotlarının haritalama yöntemi ile engebeli zeminlerde hareketi Figure 17. Movement of $\boldsymbol{a}) \mathrm{Hy} Q$ and $\boldsymbol{b})$ ANYmal robots on uneven ground by mapping method

Aceituno-Cabezas ve ark. (2018), HyQ robotunun yürüyüş hareketini ve ayak ucu kontak konumlarını eş zamanlı ve verimli bir şekilde hesaplamak amaciyla 'mixed-integer convex' isimli bir formülasyon sunmuşlardır. Düz bir zeminde belirli yürüyüş çeşitleri ile sınırlı kalmamışlar, konik yüzeyler için sürtünmeyi, yaklaşık eyleyici tork limitlerini ve yürüyüşs planlamasını birlikte ele almışlardır. Yaklaşımlarını, konveks ve düz arazi varsayımlarına yol açabilecek düzeyde optimal olmayan, kararsız, farklı zorlu arazi şartlılarında deneysel olarak doğrulamışlarıdır. Önerilen yöntemin hesaplama süresinde bir artışa sebep olmadan yürüyüş kararlılığını artırdığı̆, en karmaşık senaryolarda bile bir saniyenin altında yürüyüş planı hesaplayabildiğini ve bu sürenin benzer uygulamalara göre yaklaşık iki kat daha iyi olduğunu belirtmişlerdir. Şekil 18'de deneysel çalışmalarını gerçekleştirdikleri, zorlu arazi koşularını temsil eden, farklı yükseltilerdeki rampa, basamak ve boşluklardan oluşan parkur görülmektedir.

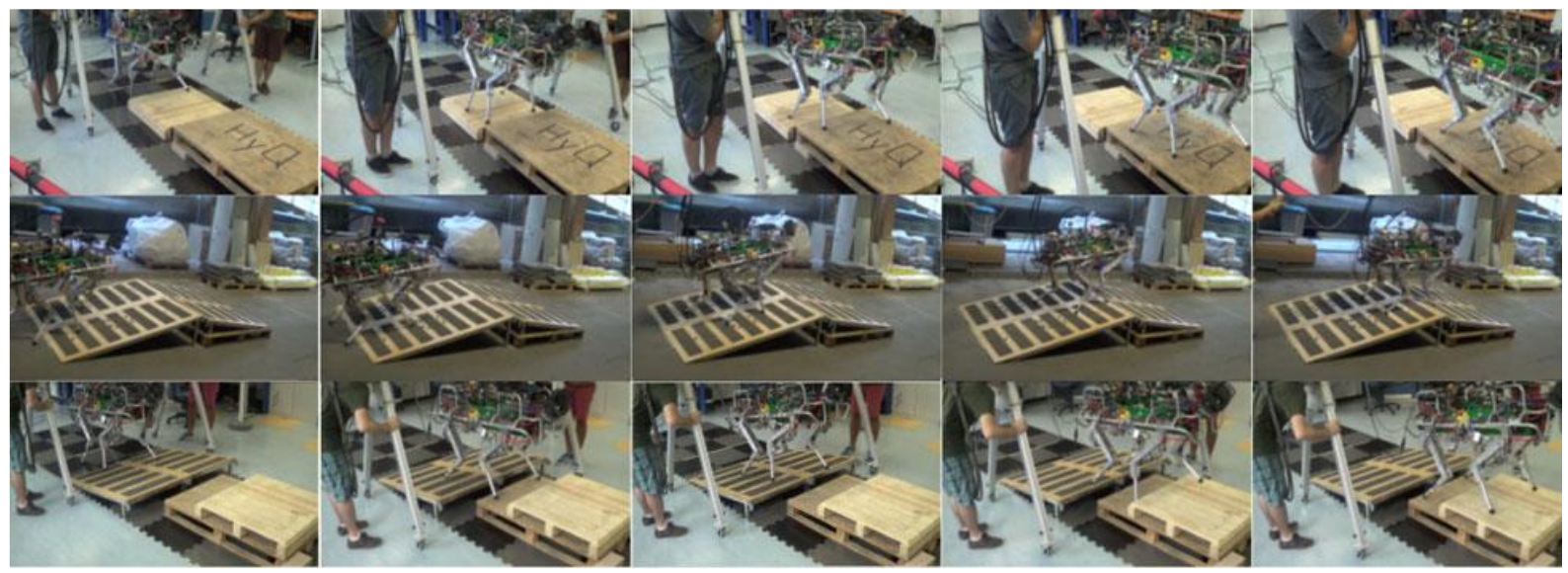

Şekil 18. $H y Q$ robotunun engebeli parkurda (rampa, basamak ve boşluk) yürüyüşü Figure 18. HyQ robot walking on a rugged parkur (ramp, step and space)

Dört ayaklı robotların düz ve engebeli yüzeylerde yürüyüş simülasyonu ile ilgili çalışmalarda; üç boyutlu katı model tasarımı, yürüyüş planlaması, kontrolcü geliştirilmesi ve gerçeğe yakın dinamik çözümlemeler için çeşitli programlar kullanılmıştır.

Adak (2013) dört ayaklı yürüyüş için, Merkezi Örüntü Üreteci tabanlı referans sentezi ve evrimsel algoritmalar ile ayarlanmasına yönelik bir çalışma sunmuştur. Çok serbestlik dereceli robot modelini Solidworks programında tasarlamış ve 3D animasyon yazılımları ile dinamik benzetimler gerçekleştirmiştir. Çalışmada, robotun dengesi ve enerji verimliliği incelenmiştir. Önerilen referans üretme yönteminin ve parametrelerinin ayarlanması için kullanılan algoritmaların yararlı olduğu bildirilmiştir (Şekil 19a). 
Dat ve Phuc (2014), küçük boyutlu bir dört ayaklı robotun modellenmesi ve MSC ADAMS ortamında, düz bir zeminde yürüyüş simülasyonuna yönelik temel bir çalışma gerçekleştirmişlerdir. Bacak eklemlerinin açısal hareketlerine ve gövde ağırlık merkezinin yörüngesine ait sonuçlar sunmuşlardır. Ayak ucu ile yüzey etkileşiminden kaynaklı dinamiklerinin ihmal edilmesi sebebiyle, çalışmanın sınırlı kaldığını ancak gelecekte yapılabilecek kontrolcü tasarımı, farklı yüzeylerde hareket, enerji tasarrufu ile ilgili çalışmalar için teorik bir temel teşkil edeceğini bildirmişlerdir (Şekil 19b).

Xu ve ark. (2016), küçük boyutlardaki dört ayaklı bir robotun katı modellemesini ve MSC ADAMS ortamında tırıs yürüyüş simülasyonunu gerçekleştirmişlerdir. Basit modellerin aksine, gerçek canlılara daha yakın bir fiziksel model tasarlamışlardır. Bacaklarının adım hareket planlamasında trigonometrik fonksiyonlar kullanmışlar, çalışmanın geliştirilmeye açık olduğunu bildirmişlerdir (Şekil 19c).

Hui-shu ve Jian-Jun (2018), yüksek tork üreten elektrik motor tahrikli, biyonik bir dört ayaklı robotun tasarımını ve yörünge kontrolünü sunmuşlardır. Koordinat dönüşümü yöntemi ile sistemin kinematik modelini oluşturmuşlardır. Adım hareketinin uçuş ve destek evreleri arasındaki ilişki analiz edilmiştir. Tırıs yürüyüş için, düşük kuvvet gerektiren ve enerji tüketimi açısından tasarruflu bir ayak yörünge planlaması geliştirmişlerdir. Sistemin sanal modeli MATLAB ortamına aktarılarak kontrolcü tasarımı gerçekleştirilmiş, robotun tırıs yürüyüşü simüle edilmiş ve enerji tüketimi incelenmiştir. Simülasyon sonuçlarına göre, önerilen yörünge planlamasının sürekli ve dengeli bir yürüyüşs sağlayabildiğini belirtmişlerdir (Şekil 19d).

Zhang ve ark. (2019), iki ayaklı insansı bir robotun dinamiklerinin incelenmesi, dengeli yürüyüşü ve yapısal tasarımı üzerine bir çalışma sunmuşlardır. Sistemin Lagrange dinamikleri de belirtilerek, CATIA yazılımında tasarlanan katı modeli üzerinden MSC ADAMS'da dinamik yürüyüş simülasyonu gerçekleştirilmiştir. (Şekil 19e).

Chen ve ark. (2019b), dayanımı artırmaya yönelik antiparallelogram bir bacak yapısı geliştirmişler, CPG tabanlı yürüyüş planlaması ile robotun statik yürüyüşten tırıs yürüyüşe geçişi için bir algoritma önermişlerdir. Simulink\&ADAMS yazılımlarının eş zamanlı koşturulmasıyla yürüyüş simülasyonları gerçekleştirmişler ve deneysel olarak doğrulamışlardır. Önerilen bacak yapısının robotun yük taşıma kapasitesini artırdığını, yürüyüş çeşitleri arasında yumuşak geçişler yapabildiğini ve eş zamanlı simülasyon yönteminin başarılı sonuçlar verdiğini bildirmişlerdir (Şekil 19f).

Wang ve ark. (2019), dört ayaklı robotlar için bacak boyunun uzayabildiği yeni bir bacak mekanizması (crank-rocker) önermişler ve ADAMS ortamında oluşturdukları sanal model üzerinden emekleme yürüyüşüne ait simülasyon çalışması gerçekleştirmişlerdir. Robot gövdesine ve ayak ucu yörüngesine ait analiz sonuçlarını sunarak, önerilen bacak mekanizmasının sorunsuz çalıştığını belirtmişlerdir (Şekil 19g).

Grzelczyk ve Awrejcewicz (2019), sekiz bacaklı bir robotun kinematik/dinamik analizlerini ve Mathematica programında tasarladıkları sade bir sanal model üzerinden yürüyüşs simülasyonunu gerçekleştirmişlerdir. Yürüyüşü, adım genişliğinin ve yüksekliğinin değişken olduğu basit sinüs fonksiyonları ile planlamışlardır. (Şekil 19h).

Chen ve ark. (2019a), dört ayaklı robot yapısına biyolojik canlılara benzer şekilde bir kafa uzvu eklemiş, kafa hareketinin etkisi üzerine deneysel ve Simulink\&ADAMS ile eş zamanlı simülasyon çalışmaları gerçekleştirmişlerdir. Kafa uzvunun ve hareketinin, gövde pozisyonunun aktif kontrolünde ve eğim açısının düzenlenmesinde etkili olduğunu, robotun daha kararlı ve dengeli hareketi için önem arz ettiğini analiz sonuçları ile birlikte belirtmişlerdir (Şekil 19k).

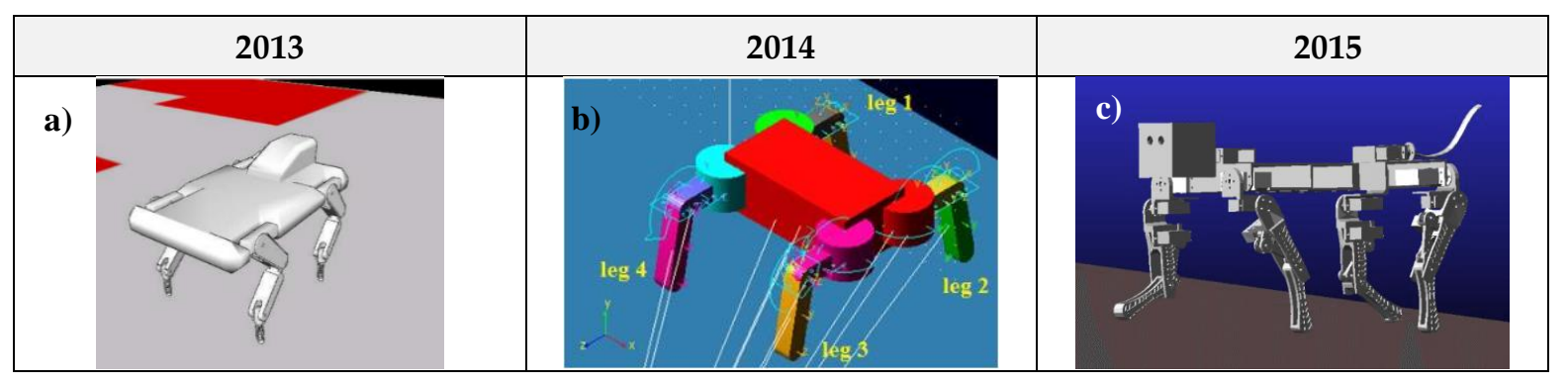




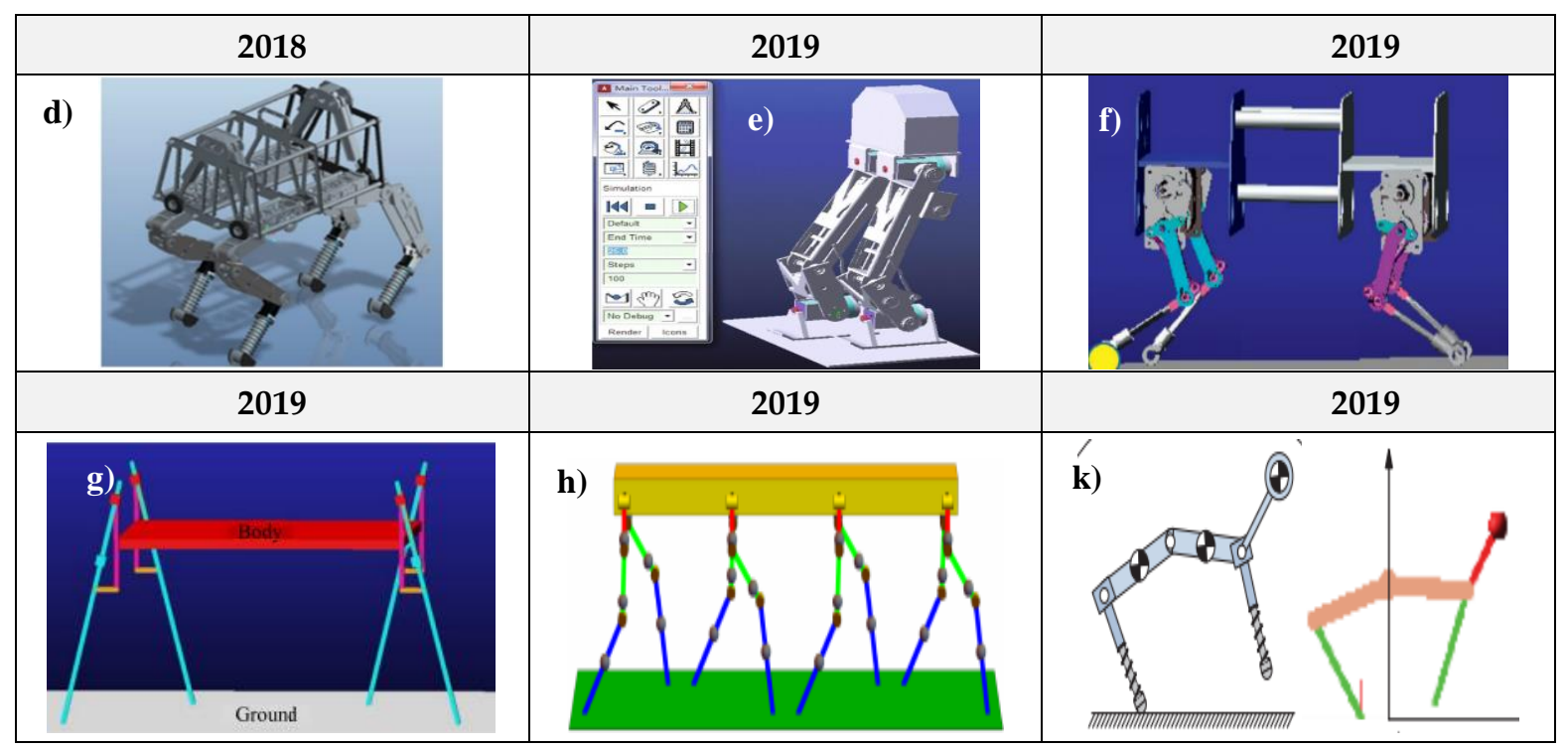

Şekil 19. Düz zeminde yürüyüş ile ilgili simülasyon çalışmaları Figure 19. The Simulation studies for walking on flat ground

Park ve Park (2012), engebeli arazilerde hareket için değişken bir empedans algoritması önermişler, dört ayaklı bir robot modelinin tırıs yürüyüşüne yönelik Simulink ortamında kontrolcü tasarımı ve bir dinamik simülatör programında simülasyon çalışmaları gerçekleştirmişlerdir. Empedans parametrelerini ikinci derecenden sistem modeli tabanlı sezgisel yöntemler ile elde etmişlerdir (Şekil 20a).

Krishna ve ark. (2013), esnek (flexible) uzuvlara sahip dört bacaklı bir robot modeli tasarlayarak, engebeli zeminlerde yürüyüş üzerine benzetim çalışmaları gerçekleştirmişlerdir. Robotun simülasyonu için MSC ADAMS ve MATLAB/Simulink programlarını eş zamanlı koşturmuşlardır. Rijit uzuvlu modellere kıyasla esnek uzuvlu yapının, enerji tasarrufu yönünden daha verimli ve engebeli arazilerde yürüyüş için daha uyumlu olduğunu belirtmişlerdir (Şekil 20b).

Wang ve ark. (2017), düzensiz zeminlerde yürüyüş için ZMP tekniği ve doğrusal ters sarkaç modeli tabanlı, gövde yörüngesinin sezgisel optimizasyonu da içeren bir yürüyüş planlaması önermişlerdir. Webot yazılımda oluşturulan sanal bir model üzerinden sistemi simüle etmişler, önerilen yürüyüş planlamasının başarılı sonuçlar verdiğini belirtmişlerdir (Şekil 20c).

Han ve ark. (2018), suyun altındaki karmaşık çalışma ortamlarında kullanılmaya yönelik geliştirdikleri, dört ayaklı bir amfibi (yüzer-gezer) robotun yürüyüş planlaması ve simülasyonuna ait bir çalışma sunmuşlardır. Çalışmada, robotun ayakları paralel bir mekanizma olarak tasarlanmış ve sistemin ters kinematik çözümleri çıkartılmıştır. Yürüyüş boyunca robot ağırlık merkezinin, ayak destek noktalarının oluşturduğu poligon içinde kalmasına dayalı bir denge ve kararlılık kriteri belirlemişlerdir. Robotun sanal modeli bir CAD programında tasarlanmış, dinamik analizi ve yürüyüş benzetimi ADAMS programında gerçekleştirilmiştir. Simülasyon sonuçları ile önerilen yürüyüş planının kararlı bir şekilde gerçekleştiğini göstermişlerdir (Şekil 20d).

Yu ve ark. (2018), eğimli zeminlerde yürüyüşte gövdenin pozisyon denetimine yönelik adaptif bir kontrolcü tasarımı ve uygulaması gerçekleştirmişlerdir. IMU sensöründen geri bildirim alan kontrolcü, gövdenin dengesini sürekli sağlamak amacıyla ayak ucu yörünge planlayıcısı ile etkileşimli olarak çalışmaktadır. Önerilen kontrolcü, Webots yazılımı ile tasarlanan dinamik model ve küçük boyutlu bir dört ayaklı robot prototipi üzerinden hem simülasyon hem de deneysel çalışmalar ile doğrulanmıştır. Sadece ayak ucu yörünge planlamasına dayalı denge kontrolcülere kıyasla, geliştirilen kontrolcünün eğimli yüzeylerde (en fazla 10 derece) gövdenin pozisyonunu ve dengesini ayarlayarak, daha yüksek hareket kabiliyetinde, daha istikrarlı ve stabil bir yürüyüş sunabildiğini belirtmişlerdir (Şekil 20e).

Li ve ark. (2019), robotun engebeli arazide hareketi boyunca ağırlık merkezinin yörünge kontrolü için hiyerarşik yapıda bir kontrol algoritması ve yürüyüş planlama tekniği önermişlerdir. Engebeler içeren bir yüzey modellemişler ve sezgisel $\mathrm{A} *$ algoritması kullanılarak ağırlık merkezine ait optimal bir yörünge 
tasarlamışlardır. Bu yörüngeyi gerçekleştirilmesi için gerekli durum değişkenleri yürüyüş boyunca hesaplatılmaktadır. Dinamik robot modeli ve engebeli yüzey OpenRAVE simülasyon programında tasarlanmış, önerilen kontrol algoritmasının performansı robotun düzlemsel statik yürüyüşü için benzetim çalışmaları ile incelenmiştir (Şekil 20f).

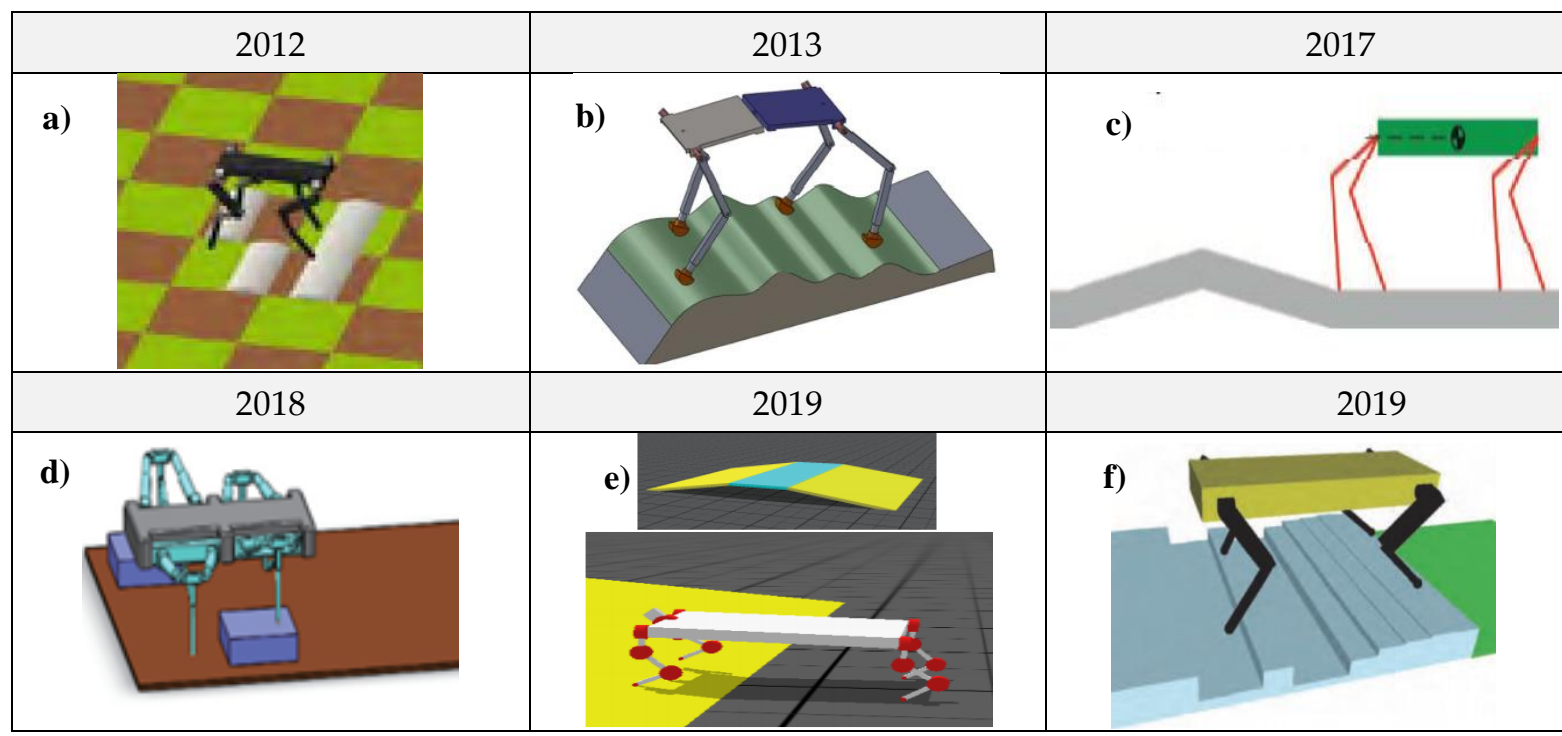

Şekil 20. Engebeli parkurlarda yürüyüş ile ilgili simülasyon çalışmaları Figure 20. Simulation studies related to walking on the rugged parkurs

Genel olarak engebeli arazilerde yürüyüş çalışmalarında; ayak tepki kuvvetlerine göre reaktif davranışlar üretmeye dayalı, küçük boyutlu arazi düzensizlikleri ile sınırlı ve yavaş çözümler geliştirilmiştir. Güncel yürüyüş planlaması yaklaşımlarında ise; ayak ucu yörünge kontrolü ile gövde denge kontrolünün birlikte ele alındığı, tüm gövdenin hareketlerini sentezlemeye odaklanılmaktadır. Bazı gelişmiş tüm gövde hareket sentezleme çalışmalarında, robot dinamiği ile arazinin özellikleri ve modellenmesi birlikte çok boyutlu bir problem olarak ele alınmıştır. Bu yaklaşımda, önceden tanımlanmış, öngörülebilir bir arazi modeli tasarlanmakta (planning) ya da robot bünyesindeki kameralar ile çevre modeli yürüyüş boyunca gerçek zamanlı haritalandırılmaktadır (mapping). Ancak deneysel uygulama maliyetleri, gelişmiş teknoloji gereksinimi nedeniyle halen oldukça yüksektir. Bu sebeple, genellikle gerçeğe yakın sanal dinamik robot modelleri üzerinden simülasyon çalışmaları yürütülmektedir.

\section{SONUÇ (CONCLUSION)}

Bu çalışma kapsamında, dört ayaklı robotlar üzerine, literatürdeki sınırlı derlemelerin aksine, temel ve güncel çalışmalar sunulmuştur. Tarih sırasına göre bacaklı robotların gelişimlerini ve teknik bilgileri içeren genel bir bakışın ardından; sistemin modellenmesi, kontrolü, eyleyici seçimi ve yürüyüşü ile ilgili deneysel ve benzetim çalışmalarının açıklandığı, geniş kapsamlı ve sistematik bir literatür derlenmiştir.

Dört ayaklı robotların, geleneksel tekerlekli/paletli araçların sağlayamayacağı avantajlara sahip olması, robotik alanındaki araştırmacıların temel motivasyon kaynağıdır. Hareketli bir gövdeye bağlı eklemli bacaklardan oluşan karmaşık yapısı ve kontrolündeki zorluklar nedeniyle dört ayaklı robotlar, günümüz robotiğinin önemli bir çalışma konusunu teşkil etmektedir.

Önemli bir kilometre taşı niteliğindeki BigDog (2005) ve ilk kapsamlı akademik çalışmaların sunulduğu HyQ (2008), StarlETH (2012) temelinde, son yılarda dört bacaklı robot alanında önemli çalışmalar sürdürülmektedir. Büyük bütçeler ve ekip çalışması gerektirmesi sebebiyle, deneysel uygulama çalışmaları sınırlı kalmakta ve dolayısıyla dört ayaklı yürüyen robotların geliştirilmesi ve ticarileşmesi yavaş ilerlemektedir. 
Geliştirilmeye açık, çok yönlü ve popüler bir konu olan bacaklı robotlar üzerine, Mete Kalyoncu ve ekibi Konya Teknik Üniversitesi bünyesinde çalışmalar sürdürmekte ve hidrolik tahrikli bir dört ayaklı robot geliştirmeyi hedeflemektedirler. Literatürdeki mevcut dört ayaklı robotların inşa süreçlerine benzer şekilde, öncelikle tek bir bacak yapınsın geliştirilmesi ve kontrolü odaklı araştırılmalar yürütmüşlerdir. Robotun yürüyüş performansını doğrudan etkileyen adım atma hareketinin iyileştirilmesine yönelik; modelleme, kinematik analiz, kontrol ve optimizasyon gibi başlıklarda birçok çalışma sunmuşlardır (Bakırcıoğlu ve ark., 2015; 2016b; 2016a; Sen ve ark., 2017a; Sen ve ark., 2017b; Sen ve Kalyoncu, 2018; Bakırcığlu ve ark., 2019; Sen ve ark., 2019; Sen ve Kalyoncu, 2019; Bakırcıŏlu, 2020; Şen, 2020).

Yakın gelecekte dört ayaklı robotların, kullanım amacına ve yerine göre, sistemin tümüne veya belirli bir kısmına yönelik; fiziksel boyutlandırma, yürüyüş planlaması, ortam haritalaması, enerji verimliliği, makine öğrenmesi, kontrolcü/boyut/süreç optimizasyonu vb. gibi birçok konuda, disiplinler arası başarılı çalışmaların yürütülmesi ve yüksek motivasyona sahip bu alanda önemli gelişimlerin kaydedilmesi kaçınılmazdır. Ülkemizde yürütülen çalışmalar henüz yeterli seviyede olmasa da, bu alandaki araştırmacıların ve desteklerin artmasıyla, sivil amaçlara ve stratejik önem arz eden savunma uygulamalarına yönelik, yerli dört ayaklı robotların geliştirilmesi ve yaygınlaşması kaçınılmaz olacaktır.

$\mathrm{Bu}$ derleme çalışmasının; ayaklı robotik alandaki Türkçe literatürün genişlemesine katkı sağlayabileceği, bu konu ile ilgili bazı kavram ve tanımlardaki eksiklikleri giderebileceği, gelecekteki çalışmalara rehberlik edebileceği, farklı yöntemlerin ve stratejilerin geliştirilmesine katkı sunabileceği öngörülmektedir.

\section{KAYNAKLAR (REFERENCES)}

Aceituno-Cabezas, B., Dai, H., Mastalli, C., Focchi, M., Radulescu, A., Caldwell, D. G., Cappelletto, J., Grieco, J. C., Fernández-López, G. ve Semini, C., 2018, "Simultaneous contact, gait, and motion planning for robust multilegged locomotion via mixed-integer convex optimization", IEEE Robotics and Automation Letters Vol. 3, No. 3, pp. 2531-2538.

Adak, Ö. K., 2013, "Quadruped locomotion reference synthesis with central pattern generators tuned by evolutionary algorithms", Ms. Thesis, Sabanci University.

Albu-Schaffer, A. ve Hirzinger, G.,"Cartesian impedance control techniques for torque controlled lightweight robots", IEEE International Conference on Robotics and Automation, Washington, DC, USA, 657-663, 2002.

Alexander, R., 1990, "Three uses for springs in legged locomotion", J International Journal of Robotics Research, Vol. 9, No. 2, pp. 53-61.

Bakırcıoğlu, V., Şen, M. A. ve Kalyoncu, M.,"Dört Ayaklı Robotun bir Bacağı için PID Kontrolcü Tasarımı ve Arı Algoritması Kullanarak Optimizasyonu", Uluslararası katılımlı 17. Makina Teorisi Sempozyumu (UMTS 2015), İzmir, Türkiye, 661-665, 2015.

Bakırcıoğlu, V., Sen, M. A. ve Kalyoncu, M.,"Optimization of PID controller based on the bees algorithm for one leg of a quadruped robot", MATEC Web of Conferences, Barcelona, Spain, 1-4, 2016a.

Bakırcıoğlu, V., Sen, M. A. ve Kalyoncu, M.,"Adaptive neural-network based fuzzy logic (ANFIS) based trajectory controller design for one leg of a quadruped robot", 5th International Conference on Mechatronics and Control Engineering, Venice, Italy, 82-85, 2016b.

Bakırcıŏlu, V., Şen, M. A. ve Kalyoncu, M.,"Yörünge Takibi İçin Kendinden Kazanç Ayarlamalı Bir PID Kontrolcü Tasarımı ve Uygulaması", Ulusal 19. Makina Teorisi Sempozyumu (UMTS 2019), İskenderun, Türkiye, 38-45, 2019.

Bakırcıoğlu, V., 2020, "Dört ayaklı hidrolik tahrikli bir robotun modellenmesi ve uygulaması", Doktora Tezi, Konya Teknik Üniversitesi, Lisansüsütü Eğitim Enstitüsü, Konya.

Bakırcıoğlu, V. ve Kalyoncu, M., 2020, "Bacaklı robotların yürüme stratejileri üzerine bir literatür taraması", J Politeknik Dergisi, Vol. 23, No.4, pp.961-986.

Barasuol, V., Buchli, J., Semini, C., Frigerio, M., De Pieri, E. R. ve Caldwell, D. G.,"A reactive controller framework for quadrupedal locomotion on challenging terrain", IEEE International Conference on Robotics and Automation, Karlsruhe,Germany, 2554-2561, 2013. 
Barasuol, V., Villarreal-Magaña, O. A., Sangiah, D., Frigerio, M., Baker, M., Morgan, R., Medrano-Cerda, G. A., Caldwell, D. G. ve Semini, C., 2018, "Highly-integrated hydraulic smart actuators and smart manifolds for high-bandwidth force control", J Frontiers in Robotics AI, Vol. 5, No. 51, pp. 1-15.

Bellicoso, C. D., Gehring, C., Hwangbo, J., Fankhauser, P. ve Hutter, M.,"Perception-less terrain adaptation through whole body control and hierarchical optimization", IEEE-RAS 16th International Conference on Humanoid Robots (Humanoids), Cancun, Mexico, 558-564, 2016.

Bloesch, M., 2017, "State estimation for legged robots-kinematics, inertial sensing, and computer vision", PhD Thesis, ETH Zurich, Switzerland.

Boaventura, T., Focchi, M., Frigerio, M., Buchli, J., Semini, C., Medrano-Cerda, G. A. ve Caldwell, D. G.,"On the role of load motion compensation in high-performance force control", IEEE/RSJ International Conference on Intelligent Robots and Systems (IROS), Algarve, Portugal, 4066-4071, 2012a.

Boaventura, T., Semini, C., Buchli, J., Frigerio, M., Focchi, M. ve Caldwell, D. G.,"Dynamic torque control of a hydraulic quadruped robot", IEEE international conference on robotics and automation (ICRA), Algarve, Portugal, 1889-1894, 2012b.

Boaventura, T., 2013, "Hydraulic compliance control of the quadruped robot HyQ", PhD Thesis, University of Genoa, Italy.

Boaventura, T., Medrano-Cerda, G. A., Semini, C., Buchli, J. ve Caldwell, D. G.,"Stability and performance of the compliance controller of the quadruped robot HyQ", IEEE/RSJ International Conference on Intelligent Robots and Systems (IROS), Tokyo, Japan, 1458-1464, 2013.

Boston Dynamics Company, 2020, "Boston Dynamics Company", Waltham, Massachusetts, ABD, https://www.bostondynamics.com:

Buchli, J., Kalakrishnan, M., Mistry, M., Pastor, P. ve Schaal, S.,"Compliant quadruped locomotion over rough terrain", IEEE/RSJ international conference on Intelligent robots and systems (IROS), Missouri, USA, 814-820, 2009.

Buehler, M., Playter, R. ve Raibert, M.,"Robots step outside", Int. Symp. Adaptive Motion of Animals and Machines (AMAM), IImenau, Germany, 1-4, 2005.

Buehler, M., Grimminger, F., Campbell, D. ve Raibert, M.,"Biologically inspired robots at boston dynamics", J bionic Industrie Congress, Berlin, Germany, 2006.

Chen, D., Gong, C., Xing, F., Zhou, C., Qi, M. ve Wang, L., 2019a, "The effect of head movement on the bounding gait of a quadruped robot with an active spine", J Advances in Mechanical Engineering, Vol. 11, No. 9, pp. 1687814019876184.

Chen, J., San, H. ve Wu, X., 2019b, "Gait regulation of a bionic quadruped robot with antiparallelogram leg based on CPG oscillator", J Complexity, Vol. 2019, No., pp. 1-11.

Cunha, T. B., Semini, C., Guglielmino, E., De Negri, V. J., Yang, Y. ve Caldwell, D. G.,"Gain scheduling control for the hydraulic actuation of the HyQ robot leg", Proc. of COBEM, Gramado, Brazil, 2009.

Dat, T. T. K. ve Phuc, T. T., 2014, "A Study on Locomotions of Quadruped Robot", In: AETA 2013: Recent Advances in Electrical Engineering and Related Sciences, Eds: Springer, 595-604.

Estremera, J. ve Waldron, K. J., 2008, "Thrust control, stabilization and energetics of a quadruped running robot", J The International Journal of Robotics Research, Vol. 27, No. 10, pp. 1135-1151.

Fankhauser, P., Hutter, M., Gehring, C., Bloesch, M., Hoepflinger, M. A. ve Siegwart, R.,"Reinforcement learning of single legged locomotion", IEEE/RSJ International Conference on Intelligent Robots and Systems, Tokyo, Japan, 188-193, 2013.

Fankhauser, P., Bjelonic, M., Bellicoso, C. D., Miki, T. ve Hutter, M.,"Robust rough-terrain locomotion with a quadrupedal robot", IEEE International Conference on Robotics and Automation (ICRA), Brisbane, Australia, 1-8, 2018.

Fankhauser, P. ve Hutter, M., 2018, "ANYmal: A unique quadruped robot conquering harsh environments", J Research Features, Vol., No. 126, pp. 54-57.

Focchi, M., 2013, "Strategies to improve the impedance control performance of a quadruped robot", $\mathrm{PhD}$ Thesis, University of Genoa, Italy. 
Focchi, M., Barasuol, V., Havoutis, I., Buchli, J., Semini, C. ve Caldwell, D. G., 2013, "Local reflex generation for obstacle negotiation in quadrupedal locomotion", In: Nature-Inspired Mobile Robotics, Eds: World Scientific, 443-450.

Focchi, M., Medrano-Cerda, G. A., Boaventura, T., Frigerio, M., Semini, C., Buchli, J. ve Caldwell, D. G., 2016, "Robot impedance control and passivity analysis with inner torque and velocity feedback loops", J Control Theory and Technology, Vol. 14, No. 2, pp. 97-112.

Focchi, M., Del Prete, A., Havoutis, I., Featherstone, R., Caldwell, D. G. ve Semini, C., 2017, "High-slope terrain locomotion for torque-controlled quadruped robots", J Autonomous Robots, Vol. 41, No. 1, pp. 259-272.

Gao, F., Qi, C., Sun, Q., Chen, X. ve Tian, X.,"A quadruped robot with parallel mechanism legs", IEEE international conference on Robotics and automation (ICRA 2014 ), Hong Kong, China, 2566-2566, 2014.

Gehring, C., Coros, S., Hutter, M., Bloesch, M., Hoepflinger, M. A. ve Siegwart, R.,"Control of dynamic gaits for a quadrupedal robot", IEEE international conference on Robotics and automation (ICRA 2013), Karlsruhe, Germany, 3287-3292, 2013.

Gehring, C., 2017, "Planning and control for agile quadruped robots", PhD Thesis, ETH Zurich, Switzerland.

Grandia, R., Farshidian, F., Dosovitskiy, A., Ranftl, R. ve Hutter, M., 2019, "Frequency-aware model predictive control", J IEEE Robotics Automation Letters, Vol. 4, No. 2, pp. 1517-1524.

Grebenstein, M., Albu-Schäffer, A., Bahls, T., Chalon, M., Eiberger, O., Friedl, W., Gruber, R., Haddadin, S., Hagn, U. ve Haslinger, R.,"The DLR hand arm system", IEEE International Conference on Robotics and Automation (ICRA 2011), Shanghai, China, 3175-3182, 2011.

Grzelczyk, D. ve Awrejcewicz, J., 2019, "Modeling and control of an eight-legged walking robot driven by driven by different gait generators", International Journal of Structural Stability and Dynamics, Vol. 19, No. 5, pp. 76-89.

Han, S., Chen, Y., Ma, G., Zhang, J. ve Liu, R., 2018, "Gait planning and simulation analysis of a new amphibious quadruped robots", J Journal of Robotics Mechatronics, Vol. 30, No. 2, pp. 257-264.

Heijnen, H., 2014, "Learning jumping maneuvers for a quadrupedal robot", MSc Thesis, ETH Zurich, Switzerland.

Hoffmann, M. ve Simanek, J., 2017, "The merits of passive compliant joints in legged locomotion: Fast learning, superior energy efficiency and versatile sensing in a quadruped robot", J Journal of Bionic Engineering, Vol. 14, No. 1, pp. 1-14.

Hogan, N., 1985a, "Impedance control: An approach to manipulation: Part I-Theory", ASME, Transactions, Journal of Dynamic Systems, Measurement, and Control, Vol. 107, No. 1, pp. 1-7.

Hogan, N., 1985b, "Impedance control: An approach to manipulation: Part II-Implementation", ASME, Transactions, Journal of Dynamic Systems, Measurement, and Control, Vol. 107, No. 1, pp. 8-16.

Hui-shu, M. ve Jian-Jun, F., 2018, "Foot trajectory planning and optimization simulation of low foot-terrain impact by quadruped robot based on the trot gait", J Journal of Electrical Electronic Engineering, Vol. 6, No. 1, pp. 26-30.

Hutter, M., Gehring, C., Bloesch, M., Hoepflinger, M. A., Remy, C. D. ve Siegwart, R., 2012a, "StarlETH: A compliant quadrupedal robot for fast, efficient, and versatile locomotion", In: Adaptive Mobile Robotics, Eds: Azad, A. K. M., USA: World Scientific, 483-490.

Hutter, M., Holenstein, C., Fenner, D., Remy, C. D., Hoepflinger, M. A. ve Siegwart, R., 2012b, "Improved efficiency in legged running using lightweight passive compliant feet", In: Adaptive Mobile Robotics, Eds, USA: World Scientific, 491-498.

Hutter, M., 2013, "StarlETH \& Co-design and control of legged robots with compliant actuation", PhD Thesis, ETH Zurich, Switzerland.

Hutter, M., Remy, C. D., Hoepflinger, M. A. ve Siegwart, R., 2013, "Efficient and versatile locomotion with highly compliant legs", J IEEE/ASME Transactions on Mechatronics, Vol. 18, No. 2, pp. 449-458. 
Hutter, M., Sommer, H., Gehring, C., Hoepflinger, M., Bloesch, M. ve Siegwart, R., 2014, "Quadrupedal locomotion using hierarchical operational space control", J The International Journal of Robotics Research, Vol. 33, No. 8, pp. 1047-1062.

Hutter, M., Gehring, C., Jud, D., Lauber, A., Bellicoso, C. D., Tsounis, V., Hwangbo, J., Bodie, K., Fankhauser, P. ve Bloesch, M.,"Anymal-a highly mobile and dynamic quadrupedal robot", IEEE/RSJ International Conference on Intelligent Robots and Systems (IROS 2016), Daejeon, South Korea, 38-44, 2016.

Hyon, S., Abe, S. ve Emura, T.,"Development of a biologically inspired biped robot KenkenII", Japan-France Congress on Mechatronics \& 4th Asia Europe Congress on Mechatronics, Fukuoka, Japan, 404-409, 2003a.

Hyon, S. H., Emura, T. ve Mita, T., 2003b, "Dynamics-based control of a one-legged hopping robot", J Proceedings of the Institution of Mechanical Engineers, Part I: Journal of Systems Control Engineering, Vol. 217, No. 2, pp. 83-98.

Kalakrishnan, M., Buchli, J., Pastor, P., Mistry, M. ve Schaal, S., 2011, "Learning, planning, and control for quadruped locomotion over challenging terrain", J The International Journal of Robotics Research, Vol. 30, No. 2, pp. 236-258.

Kazerooni, H., Houpt, P. ve Sheridan, T., 1986, "Robust compliant motion for manipulators, Part II: Design method", J IEEE Journal on Robotics Automation, Vol. 2, No. 2, pp. 93-105.

Khan, H., 2015, "MiniHyQ - development of a lighweight highly-dynamic hydraulic quadruped robot", PhD Thesis, University of Genoa, Italy.

Khan, H., Kitano, S., Frigerio, M., Camurri, M., Barasuol, V., Featherstone, R., Caldwell, D. G. ve Semini, C.,"Development of the lightweight hydraulic quadruped robot-MiniHyQ", IEEE International Conference on Technologies for Practical Robot Applications (TePRA 2015), Boston, MA USA, 1-6, 2015.

Khatib, O., 1987, "A unified approach for motion and force control of robot manipulators: The operational space formulation", J IEEE Journal on Robotics Automation, Vol. 3, No. 1, pp. 43-53.

Kim, J. T., San Cho, J., Park, B.-Y., Park, S. ve Lee, Y.,"Experimental investigation on the design of leg for a hydraulic actuated quadruped robot", IEEE 44th International Symposium on Robotics (ISR 2013), Seoul, Korea, 1-5, 2013.

Kimura, H., Akiyama, S. ve Sakurama, K., 1999, "Realization of dynamic walking and running of the quadruped using neural oscillator", J Autonomous Robots, Vol. 7, No. 3, pp. 247-258.

Kitano, S., Hirose, S., Horigome, A. ve Endo, G., 2016, "TITAN-XIII: Sprawling-type quadruped robot with ability of fast and energy-efficient walking", J Robomech Journal, Vol. 3, No. 8, pp. 1-16.

Koivumäki, J., Mattila, J., Semini, C. ve Caldwell, D. G.,"Stability-guaranteed nonlinear model-based control of hydraulically actuated lightweight structures", ASME/BATH Symp. on Fluid Power and Motion Control (FPMC 2017), Florida, USA, 2017.

Krishna, P. M., Kumar, R. P. ve Srivastava, S., 2013, Dynamic gaits and control in flexible body quadruped robot. 1st International Conference on Machines and Mechanisms (iNaCoMM2013). IIT Roorkee, India: 706-713.

Krupp, B. T. ve Pratt, J. E.,"A power autonomous monopedal robot", The International Society for Optical Engineering (SPIE 2006), Washington DC, USA, 1-12, 2006.

Lei, J., Zhu, J., Xie, P. ve Tokhi, M. O., 2017, "Joint variable stiffness of musculoskeletal leg mechanism for quadruped robot", J Advances in Mechanical Engineering, Vol. 9, No. 4, pp. 1-11.

Li, X., Gao, H., Li, J., Wang, Y. ve Guo, Y., 2019, "Hierarchically planning static gait for quadruped robot walking on rough terrain", J Journal of Robotics, Vol. 2019, No., pp. 1-12.

Liston, R. A. ve Mosher, R. S., 1968, A versatile walking truck. In Proceedings of the Transportation Engineering Conference. Institution of Civil Engineers,London, England.

Mastalli, C., 2017, "Planning and Execution of Dynamic Whole-Body Locomotion on Challenging Terrain", PhD Thesis, University of Genoa, Italy. 
Mastalli, C., Havoutis, I., Focchi, M., Caldwell, D. ve Semini, C., 2020, "Motion planning for quadrupedal locomotion: coupled planning, terrain mapping and whole-body control", arXiv preprint arXiv:2003.05481., Vol., No., pp. 1-17.

McGeer, T., 1990, "Passive dynamic walking", The International Journal of Robotics Research, Vol. 9, No. 2, pp. 62-82.

Michele, F., 2013, "Strategies to improve the impedance control performance of a quadruped robot", PhD Thesis, University of Genoa, Italy.

Mistry, M., Buchli, J. ve Schaal, S.,"Inverse dynamics control of floating base systems using orthogonal decomposition", IEEE International Conference on Robotics and Automation (ICRA 2010), Anchorage, Alaska,, 3406-3412, 2010.

Niquille, S. C., 2019, "Regarding the pain of spotmini: Or what a robot's struggle to learn reveals about the built environment", J Architectural Design, Vol. 89, No. 1, pp. 84-91.

Orsolino, R., 2019, "Actuation-Aware Simplified Dynamic Models for Robotic Legged Locomotion", PhD Thesis, University of Genoa, Italy.

Pan, X., Zhang, T., Ichter, B., Faust, A., Tan, J. ve Ha, S., 2020, "Zero-shot imitation learning from demonstrations for legged robot visual navigation", J arXiv preprint arXiv:.12971v2, Vol., No., pp. $1-7$.

Park, H.-W., Chuah, M. Y. ve Kim, S.,"Quadruped bounding control with variable duty cycle via vertical impulse scaling", IEEE/RSJ International Conference on Intelligent Robots and Systems (IROS 2014), Illinois, USA, 3245-3252, 2014.

Park, J. ve Park, J. H.,"Impedance control of quadruped robot and its impedance characteristic modulation for trotting on irregular terrain", IEEE/RSJ International Conference on Intelligent Robots and Systems (IROS 2012), Algarve, Portugal, 175-180, 2012.

Playter, R., Buehler, M. ve Raibert, M.,"Bigdog", Society of Photo-Optical Instrumentation Engineers (SPIE) 6230, Florida, United States, 2006.

Poulakakis, I., Smith, J. A. ve Buehler, M., 2005, "Modeling and experiments of untethered quadrupedal running with a bounding gait: The Scout II robot", J The International Journal of Robotics Research, Vol. 24, No. 4, pp. 239-256.

Pratt, G. A. ve Williamson, M. M.,"Series elastic actuators", International Conference on Intelligent Robots and Systems (IROS 1995), Pittsburgh, PA, USA, 399-406, 1995.

Pratt, G. A., 2002, "Low impedance walking robots", J Integrative Comparative Biology, Vol. 42, No. 1, pp. 174-181.

Pratt, J., Chew, C.-M., Torres, A., Dilworth, P. ve Pratt, G., 2001, "Virtual model control: An intuitive approach for bipedal locomotion", J The International Journal of Robotics Research, Vol. 20, No. 2, pp. 129-143.

Raibert, M., 1986, "Legged robots that balance", The MIT press, pp. 223.

Raibert, M., Blankespoor, K., Nelson, G. ve Playter, R., 2008, "BigDog, the rough-terrain quadruped robot", IFAC Proceedings Volumes, Vol. 41, No. 2, pp. 10822-10825.

Rebula, J. R., Neuhaus, P. D., Bonnlander, B. V., Johnson, M. J. ve Pratt, J. E.,"A controller for the littledog quadruped walking on rough terrain", IEEE International Conference on Robotics and Automation (ICRA 2007), Roma, Italy, 1467-1473, 2007.

Remy, C. D., Baur, O., Latta, M., Lauber, A., Hutter, M., Hoepflinger, M. A., Pradalier, C. ve Siegwart, R., 2011, "Walking and crawling with ALoF- A robot for autonomous locomotion on four legs", The International Journal Of Robotics Research And Application, Vol. 47, No. 1, pp. 501-508.

Rong, X., Li, Y., Ruan, J. ve Li, B., 2012, "Design and simulation for a hydraulic actuated quadruped robot", J Journal of mechanical science technology, Vol. 26, No. 4, pp. 1171-1177.

Schaal, S., 2009, "The SL simulation and real-time control software package", J University of Southern California, Technical Report. 
Semini, C., Tsagarakis, N. G., Vanderborght, B., Yang, Y. ve Caldwell, D. G.,"HyQ-Hydraulically actuated quadruped robot: Hopping leg prototype", 2nd IEEE RAS \& EMBS International Conference on Biomedical Robotics and Biomechatronics (BioRob 2008), Scottsdale, AZ, USA, 593-599, 2008.

Semini, C., 2010, "HyQ-design and development of a hydraulically actuated quadruped robot", PhD Thesis, University of Genoa, Italy.

Semini, C., Tsagarakis, N. G., Guglielmino, E., Focchi, M., Cannella, F. ve Caldwell, D. G., 2011, "Design of HyQ-A hydraulically and electrically actuated quadruped robot", J Proceedings of the Institution of Mechanical Engineers, Part I: Journal of Systems Control Engineering, Vol. 225, No. 6, pp. 831-849.

Semini, C., Barasuol, V., Boaventura, T., Frigerio, M., Focchi, M., Caldwell, D. G. ve Buchli, J., 2015a, "Towards versatile legged robots through active impedance control", J The International Journal of Robotics Research, Vol. 34, No. 7, pp. 1003-1020.

Semini, C., Goldsmith, J., Manfredi, D., Calignano, F., Ambrosio, E. P., Pakkanen, J. ve Caldwell, D. G.,"Additive manufacturing for agile legged robots with hydraulic actuation", 17th International Conference on Advanced Robotics (ICAR 2015), Istanbul, Turkey, 123-129, $2015 \mathrm{~b}$.

Semini, C., Goldsmith, J., Rehman, B. U., Frigerio, M., Barasuol, V., Focchi, M. ve Caldwell, D. G.,"Design overview of the hydraulic quadruped robots HyQ2MAX and HyQ2CENTAUR", 15th Scandinavian International Conference on Fluid Power, Tampere, Finland, 20-22, 2015c.

Semini, C., Barasuol, V., Goldsmith, J., Frigerio, M., Focchi, M., Gao, Y. ve Caldwell, D. G., 2017, "Design of the hydraulically actuated, torque-controlled quadruped robot HyQ2max", J IEEE/ASME Transactions on Mechatronics, Vol. 22, No. 2, pp.635-646.

Semini, C., Barasuol V., Focchi, M., Boelens, C., Emara, M., Casella , S., Villarreal, O., Orsolino, R., Fink, G., Fahmi, S., Medrano-Cerda, G., Caldwell, D. G., Sangiah, D., Lesniewski, J., Fulton, K., Donadon, M. ve Baker, M., 2019, "Brief Introduction to the Quadruped Robot HyQReal", Istituto di Robotica e Macchine Intelligenti 3D.

Sen, M. A., Bakircioglu, V. ve Kalyoncu, M., 2017a, "Inverse kinematic analysis of a quadruped robot", J International journal of scientific technology research, Vol. 6, No. 09, pp. 2277-8616.

Sen, M. A., Bakırcıoğlu, V. ve Kalyoncu, M., 2017b, Design and simulation impedance controller for trajectory control with obstacle of quadruped robot's leg. International Advanced Researches \& Engineering (IAREC 2017). Osmaniye, Turkey: 558-568.

Sen, M. A. ve Kalyoncu, M., 2018, "Optimal tuning of PID controller using grey wolf optimizer algorithm for quadruped robot", J Balkan Journal of Electrical Computer Engineering, Vol. 6, No. 1, pp. 29-35.

Sen, M. A., Bakırcıoğlu, V. ve Kalyoncu, M., 2019, "Three degree of freedom leg desıgn for quadruped robots and fractional order PID (PI $\lambda \mathrm{D} \mu)$ based control", Konya Journal of Engineering Sciences, Vol. 8, No. 2, pp. 237-247.

Sen, M. A. ve Kalyoncu, M., 2019, "Grey wolf optimizer based tuning of a hybrid LQR-PID controller for foot trajectory control of a quadruped robot", J Gazi University Journal of Science, Vol. 32, No. 2, pp. 674-684.

Seok, S., Wang, A., Chuah, M. Y., Otten, D., Lang, J. ve Kim, S.,"Design principles for highly efficient quadrupeds and implementation on the MIT Cheetah robot", IEEE International Conference on Robotics and Automation (ICRA 2013), Karlsruhe, Germany, 3307-3312, 2013.

Silva, M. F. ve Tenreiro Machado, J. A., 2007, "A historical perspective of legged robots", J Journal of Vibration Control, Vol. 13, No.9-10, pp. 1447-1486.

Şen, M. A., 2020, "Dört Ayaklı Bir Robotun Engebeli Yüzeylerde Yürüme Analizi ve Kontrolü", Doktora Tezi, Konya Teknik Üniversitesi, Lisansüsütü Eğitim Enstitüsü, Konya.

Tsagarakis, N. G., Sardellitti, I. ve Caldwell, D. G.,"A new variable stiffness actuator (CompAct-VSA): design and modelling", IEEE/RSJ International Conference on Intelligent Robots and Systems (IROS 2011), San Francisco, CA, USA, 378-383, 2011.

Ubellacker, W. L., 2016, "Real-time quadruped gait controller for rough terrain locomotion", MSc Thesis, Massachusetts Institute of Technology, Massachusetts, USA. 
Ugurlu, B., Havoutis, I., Semini, C. ve Caldwell, D. G.,"Dynamic trot-walking with the hydraulic quadruped robot-HyQ: Analytical trajectory generation and active compliance control", IEEE/RSJ International Conference on Intelligent Robots and Systems (IROS 2013), Tokyo, Japan 6044-6051, 2013.

Ur Rehman, B., Focchi, M., Frigerio, M., Goldsmith, J., Caldwell, D. G. ve Semini, C.,"Design of a hydraulically actuated arm for a quadruped robot", 18th International Conference on CLAWAR 2015, Zhejiang Province, China, 283-290, 2016.

Villarreal, O., Barasuol, V., Wensing, P. ve Semini, C., 2020, "MPC-based Controller with Terrain Insight for Dynamic Legged Locomotion", J arXiv preprint arXiv:.13842v2, pp. 1-8.

Wagner, L., Fankhauser, P., Bloesch, M. ve Hutter, M., 2017, "Foot contact estimation for legged robots in rough terrain", In: Advances in Cooperative Robotics, Eds: World Scientific, 395-403.

Wang, Y., Wei, Q. ve Ma, T.,"Crawling gait planning and simulation analysis of closed-chain walking leg robot", IOP Conference Series: Materials Science and Engineering, Kazimierz Dolny, Poland, 012072, 2019.

Wang, Z., Sun, C., Deng, G. ve Zhang, A.,"Locomotion planning for quadruped robot over rough terrain", Chinese Automation Congress (CAC 2017), Jinan, China, 3170-3173, 2017.

Whitney, D. E., 1985, Historical perspective and state of the art in robot force control. IEEE International Conference on Robotics and Automation (ICRA 1985). Missouri, USA. 2: 262-268.

Winkler, A., Havoutis, I., Bazeille, S., Ortiz, J., Focchi, M., Dillmann, R., Caldwell, D. ve Semini, C.,"Path planning with force-based foothold adaptation and virtual model control for torque controlled quadruped robots", IEEE International Conference on Robotics and Automation (ICRA 2014), Hong Kong, China, 6476-6482, 2014.

Winkler, A. W., Mastalli, C., Havoutis, I., Focchi, M., Caldwell, D. G. ve Semini, C.,"Planning and execution of dynamic whole-body locomotion for a hydraulic quadruped on challenging terrain", IEEE International Conference on Robotics and Automation (ICRA 2015), Seattle, WA, USA, 5148-5154, 2015.

Winter, D. A., 1995, "Human balance and posture control during standing and walking", J Gait posture, Vol. 3, No. 4, pp. 193-214.

Xu, P., Song, R., Mao, S., Rong, X. ve Li, Y.,"Quadruped robot mechanism design and motion simulation based on SolidWorks and Adams", Proceedings of the 18th International Conference on CLAWAR 2015, Zhejiang Province, China, 454-460, 2016.

Yamazaki, K. S., 1999, "The design and control of Scout I, a simple quadruped robot", PhD Thesis, McGill University, Canada, UK.

Yu, C., Zhou, L., Qian, H. ve Xu, Y.,"Posture correction of quadruped robot for adaptive slope walking", IEEE International Conference on Robotics and Biomimetics (ROBIO 2018), Kuala Lumpur, Malaysia, 1220-1225, 2018.

Zhang, B., Shao, C., Li, Y., Tan, H. ve Jiang, D. J. J. o. S. J. U., 2019, "Dynamic Simulation Analysis of Humanoid Robot Walking System Based on ADAMS", Vol. 24, No. 1, pp. 58-63.

Zhang, Z. G., Kimura, H. ve Takase, K., 2006, "Adaptive running of a quadruped robot using forced vibration and synchronization", J Journal of Vibration Control, Vol. 12, No. 12, pp. 1361-1383. 